\title{
Do cost-based pricing biases persist in laboratory markets?
}

\author{
William S. Waller ${ }^{\mathrm{a}, *}$, Brian Shapiro ${ }^{\mathrm{b}}$, Galen Sevcik ${ }^{\mathrm{c}}$ \\ ${ }^{\mathrm{a}}$ Department of Accounting, University of Arizona, McClelland Hall, 301X, Tuscon, AZ 85721, USA \\ ${ }^{\mathrm{b}}$ University of Minnesota, USA \\ ${ }^{\mathrm{c}}$ Georgia State University, USA
}

\begin{abstract}
Past accounting experiments have demonstrated significant effects of absorption vs variable costing systems on pricing decisions, but in individual settings that suppressed market features. The main finding of the current study is that a cost-based pricing bias did not persist in laboratory product markets. Given the opportunity to learn from profit and market feedback, sellers revised their price offers toward optimum in a manner that compensated for absorption vs variable cost signals. The effects of demand conditions, as revealed through actual trades, dominated the effects of alternative costing systems. (C) 1999 Elsevier Science Ltd. All rights reserved.
\end{abstract}

\section{Introduction}

A basic issue in accounting is whether alternative information systems affect economic decisions. When examining this issue, it is important to consider the organizational or institutional setting of the decision-maker, e.g. type of firm or market (Hopwood, 1978; Libby, 1990). In management accounting, there is much interest in how alternative costing systems affect pricing decisions (Kaplan \& Atkinson, 1998). Because pricing decisions naturally occur in markets, research on costbased pricing should consider the essential features of the market setting in which such decisions are made. The setting is important for three reasons. First, markets typically give sellers access to information other than accounting signals, e.g. past prices and offers, which may moderate or overwhelm the effects of costing systems. Second,

* Corresponding author. Fax: + 1-520-621-3742.

E-mail address: wwaller@bpa.arizona.edu (W.S. Waller) pricing decisions require sellers to set goals as well as process accounting signals, e.g. a $20 \%$ profit markup on unit cost. Under market pressure, sellers with alternative costing systems may compensate for unit-cost differences when setting the profit goal. Third, markets often give sellers the opportunity to learn from feedback, with the consequence that initially observed effects of costing systems do not persist.

Experimental research strives for internal validity through the manipulation of independent variables, e.g. alternative costing systems, and careful observation of behavioral effects, e.g. pricing decisions, controlling for other factors. But, such concern for internal validity does not immunize experimentalists from the need to consider the organizational or institutional setting of the decision-maker (Swieringa \& Weick, 1982). Regarding cost-based pricing, there has been a long line of accounting experiments providing evidence about the effects of absorption vs variable costing systems on pricing decisions in individual settings (Ashton, 1976, 1981; Barnes \& Webb, 1986; 
Dyckman, Hoskin \& Swieringa, 1982; Hilton, Swieringa \& Turner, 1988; Swieringa, Dyckman \& Hoskin, 1979; Turner \& Hilton, 1989). The evidence suggests that these alternative costing systems cause pricing biases, e.g. systematically higher price offers under absorption costing. As reviewed below, however, past experiments did not incorporate essential market features such as actual seller competition, price revision in light of feedback, and the threat of bankruptcy. The question remains as to whether cost-based pricing biases persist in market settings.

This study contributes evidence about the effects of absorption vs variable costing on pricing decisions in laboratory product markets. In each of eight markets with a posted-price institution, ten sellers were randomly assigned absorption or variable costing systems, and competed by making offers to sell units at a price equal to the reported unit cost plus a profit markup. Although their costing systems differed, all sellers faced the same increasing marginal cost function with an unavoidable fixed cost and a variable cost that depended on unit sales. Sellers realized a profit or loss from their trades, observed other trades, and revised their offers, for each of 48 periods (six sets of eight periods), and ultimately survived or went bankrupt. Predictions of optimal prices and quantities at competitive equilibrium were derived independently of costing systems. Demand was manipulated within and between markets. The within-market manipulation involved a random shift for each set of periods. This permitted repeated observations of seller learning (i.e. price revision) from the starting point of ignorance about demand. The between-market manipulation involved the threat of bankruptcy; demand conditions implied that only five (ten) optimizing sellers could break even on average in the harsh (lenient) markets. This permitted observation of whether seller learning accelerated when the threat of bankruptcy was higher.

Comparable to many laboratory-market studies (Davis \& Holt, 1993), sellers' price offers converged toward optimum in each set of periods. Overall, the median price error (a seller's price offer vs the optimal price) decreased by more than $80 \%$ from period 1 to 8 of a set. Typically, sellers who failed to make a sale lowered their price offers, resulting in more units to be sold and market efficiency (actual profit as a percentage of maximum profit) to approach $100 \%$. Absorption vs variable costing systems caused a bias in price offers only in the first period of the first set, when sellers had not yet observed actual trades and were ignorant about demand. The effects of demand conditions, as revealed through trading, quickly overwhelmed this bias, and the costing systems had no long-run effect on profitability or survival. Price revisions from one period to the next were strongly associated with both profit variances (a seller's actual vs target profit) and price variances (a seller's price offer vs the average market price). The threat of bankruptcy accelerated seller learning, in that relative price revision from period 1 to 2 was larger in the harsh vs lenient markets, although this effect reversed in the next few periods.

Regarding cost-based pricing biases, this study's results resembled those of past experiments only in the initial period. Given profit and market feedback, the bias did not persist as sellers revised their price offers toward optimum without regard to absorption vs variable cost signals. Further, the bias did not re-emerge in the first period of subsequent sets, when sellers again were ignorant about demand. The effects of alternative costing systems on pricing decisions apparently depend on individual vs market settings. As discussed below, there are crucial differences between individual and market settings, including trading institutions, incentives, and information for learning. The issue of whether decision behavior observed in individual settings persists in markets has attracted considerable attention from economists and psychologists (Hogarth \& Reder, 1986; Lopes, 1994; Smith, 1991). This study adds to the growing literature on the issue (Camerer, 1987, 1992; Camerer, Loewenstein \& Weber, 1989; Cox \& Grether, 1996; Ganguly, Kagel \& Moser, 1994; Kachelmeier, 1996). Specifically, the strong association between sellers' price revisions and feedback variances supports the adaptive learning model underlying the behavioral theory of the firm (Cyert \& March, 1992; Levitt \& March, 1988). Seller learning is an important market mechanism 
(Tversky \& Kahneman, 1986), which helps to reconcile the view of many economists that markets induce optimal decisions at equilibrium and the view of many psychologists that individual decisions are subject to bias. At least in this study's market setting, simple learning processes were effective in moving biased decisions toward optimal decisions. Whether learning is effective in more complex settings, e.g. when sellers compete in multiple product markets, is a question for future research.

The rest of the paper is organized as follows. Section 2 discusses differences between individual and market settings, reviews past accounting experiments on absorption vs variable costing, and states the hypotheses. Sections 3 and 4 describe the experiment's method and results, respectively. The last section provides concluding remarks.

\section{Literature review and hypotheses}

\subsection{Individual and market settings}

Psychology and economics both focus on individual decision behavior, but from fundamentally different perspectives (Lopes, 1994). Psychologists view individuals as cognitive information processing systems that translate environmental stimuli, joined with prior knowledge, into behavioral responses. Such processing involves heuristics, or simplified procedures, that economize on a limited capacity for encoding, retrieving, and manipulating information (Simon, 1978, 1986). Although generally effective, heuristics sometimes produce biased judgments and decisions, relative to probability and utility theory (Tversky \& Kahneman, 1974, 1986). Many psychological experiments have demonstrated such biases in individual settings (Arkes \& Hammond, 1986; Kahneman, Slovic \& Tversky, 1982). In contrast, economists build theories of aggregate outcomes, e.g. equilibrium prices and quantities in competitive markets, based on the assumption that individuals make rational choices in terms of utility maximization (Milgrom $\&$ Roberts, 1992). The difference in perspectives has led to considerable debate on the behavioral foundations of microeconomics and on whether biases observed in individual settings persist in markets (Hogarth \& Reder, 1986).

A contentious view of the debate sees a contest between psychology and economics regarding the empirical validity of the rational-choice model. A more productive and integrative view seeks ways in which the limitations of psychology are alleviated by economics, and vice versa (Smith, 1991). Drawing from experimental economics, Smith stated two broad conclusions from hundreds of laboratory-market studies: economic theory generally provides a correct first approximation of equilibrium outcomes, but is weak in describing the processes of convergence and economizing on decision cost. Economic theory derives predictions using the principle of methodological individualism (Blaug, 1992); i.e. efficient equilibrium outcomes are implied by the assumedly rational choices of individuals, along with other conditions. Such derivation is open as to the actual causal processes that produce aggregate outcomes and, specifically, does not require a disequilibrium process involving rational choices by actual individuals (Nelson \& Winter, 1982). These considerations suggest limitations in both economics and psychology. Although generally successful in predicting equilibria, economic theory provides limited insight into causal processes. Although validly describing cognitive processes and constraints, psychological experiments are limited by usage of settings that isolate the individual from market forces. From an integrative perspective, a key question is:

Why is it that human subjects in the laboratory frequently violate the canons of rational choice when tested as isolated individuals, but in the social context of exchange institutions serve up decisions that are consistent (as though by magic) with predictive models based on individual rationality (Smith, 1991, p. 894)?

To answer this question requires examination of the market processes by which equilibrium outcomes emerge. In this regard, experimental economics emphasizes the role of trading institutions (i.e. the 
rules governing trades between sellers and buyers), incentives, and information for learning.

Besides testing equilibrium predictions, a major contribution of experimental economics has been extensive empirical evidence regarding the effects of trading institutions on the rate and pattern of market convergence. For example, double auctions in which each subject may offer or accept either bids or asks induce rapid convergence, whereas posted-price institutions in which sellers make take-it-or-leave-it offers induce slower convergence. Perhaps the most striking demonstrations of institutional effects have been market simulations with zero-intelligence traders programmed to generate random bids and asks, subject to only a budget constraint and an endogenous choice set (Gode \& Sunder, 1993; see also Jamal \& Sunder, 1996). Using double auctions, these simulations achieved almost $100 \%$ efficiency, despite the absence of arbitrage, bankruptcy, incentives, learning, or even usage of heuristics. Efficient market outcomes emerged as a result of the institution and environment, not from rational choice by individuals (cf. Simon, 1982, 1986; Smith, 1991). Institutional effects are a primary difference between individual and market settings.

Although not necessary for market efficiency, incentives and learning can strongly influence the convergence process. Standard procedures in experimental economics include subject payments under performance-based incentives and repeated trading periods with feedback to allow for learning (Davis \& Holt, 1993; Friedman \& Sunder, 1994). Regarding incentives, in contrast with the mixed evidence in psychology (Bonner, Young \& Hastie, 1996; Hogarth \& Reder, 1986), the preponderance of evidence in experimental economics indicates that incentives matter in markets, by reducing inconsistencies between actual and rational choice (Smith \& Walker, 1993). The effects of incentives in markets may be enhanced by the presence of multiple, self-interested participants who affect each other's payoff through the institution (Frey \& Eichenberger, 1994). At a minimum, incentives reduce noise when greater cognitive effort can improve performance. Regarding learning, the typical pattern of con- vergence in laboratory markets is for efficiency to be relatively low in the first trading period, increase significantly in the next few periods, and increase more gradually in subsequent periods. While this pattern presumably reflects subjects' revisions in bids and asks in light of performance feedback, experimental economics contains few systematic attempts to describe individual learning processes and their relation to market convergence. ${ }^{1}$ This deficiency suggests an opportunity for psychology to inform economics about adaptation by cognitive information processing systems. As with incentives, however, generalization from individual to market settings is problematic. A primary difference is that learning is an interactive, social phenomenon in markets where each subject's performance feedback and observations of market activity depend on the actions of others through the institution.

A growing number of experiments have examined whether biases observed in individual settings persist in market settings (Camerer, 1987; Camerer et al., 1989; Cox \& Grether, 1996; Duh \& Sunder, 1986; Ganguly et al., 1994; Kachelmeier, 1996). For example, psychological experiments have shown that subjects in individual settings make probability judgments using a representativeness heuristic which causes biases such as ignoring base rates (Kahneman \& Tversky, 1972). Camerer (1987) ran a series of markets in which subjects traded assets that paid a state-dependent dividend. Demand for the assets depended on subjects' posterior probabilities given sample information, and parameters were specified such that usage of representativeness vs Bayesian revision implied different equilibrium prices. Camerer (1987) found that prices tended toward Bayesian predictions, with only a small degree of bias attributable to representativeness. Duh and Sunder (1986) had similar results. In contrast, Ganguly et al. (1994) reported that prices in their asset markets were persistently closer to representativeness-based predictions than Bayesian predictions, especially in markets where representativeness implied higher

1 To date, game experiments have emphasized subject learning far more than market experiments have (see Erev \& Roth, 1998; Roth \& Erev, 1995). 
prices. Relatively few subjects made unbiased, pretrading probability judgments, even after 16 periods, and these subjects were not sufficiently active to drive prices to Bayesian predictions.

Preference reversal is another frequent finding in individual settings (Lichtenstein \& Slovic, 1971; Slovic \& Lichtenstein, 1983). Suppose subjects are asked to perform two tasks: (1) choose lottery A with a high probability of a moderate payoff or lottery B with a lower probability of a higher payoff, and (2) value A and B on a monetary scale. Many subjects choose A but place a higher value on B. Cox and Grether (1996) examined preference reversals by manipulating the response mode (choice vs valuation), monetary incentives (strong vs moderate vs none), and setting (individual vs market). There were five task repetitions to allow for learning. The results showed high rates of preference reversal in the first repetition, but much lower rates by the fifth repetition, especially in market settings. As subjects in markets repeated the task, they incorporated past prices into their offers.

A final example concerns the sunk-cost fallacy whereby an individual's decision is affected by a normatively irrelevant historical cost (Arkes \& Blumer, 1985). Kachelmeier (1996) ran a series of markets to examine one aspect of sunk cost. Subjects were either sellers or buyers of a security. Prior to trading, each seller was assigned one unit of the security, an unavoidable sunk cost, and a redemption value (opportunity cost) in case of no sale. A between-market manipulation was cost of sale (sunk cost vs opportunity cost) in a profit feedback report, although the formula for subject payments did not depend on this variable. The results showed that bids and asks were persistently higher in the markets with the sunk-cost format. Sellers' aversion to a paper loss produced an upward bias in asks, and buyers reacted by raising bids. However, the bias did not affect market prices or efficiency, because of shifts in the percentages of seller- vs buyer-initiated trades.

In sum, experimental economics provides evidence from hundreds of market studies (not focused on individual biases) that generally confirms the equilibrium predictions, and indirectly the rationality assumption, of economic theory.
The much smaller group of studies focused on individual biases in markets provides more equivocal evidence. Some studies found that individual biases were reduced, if not eliminated, in market settings. Other studies found that individual biases had persistent effects on market offers and prices. Before drawing conclusions, more research is needed on the mechanisms that drive markets and the conditions under which these mechanisms induce or fail to induce rational decisions.

\subsection{Cost-based pricing}

Surveys indicate that firms predominantly use pricing policies that set initial prices equal to unit cost plus target profit (see Dorward, 1987, for a review). For example, Govindarajan and Anthony (1983) surveyed over 500 industrial firms of the Fortune 1000, asking respondents to specify "the method that comes closest to the one you usually use in arriving at the normal selling price for your typical product." Variations of absorption (variable) cost-based pricing were specified by $83 \%$ $(17 \%)$ of the respondents. Shim and Sudit (1995) similarly surveyed 141 firms; 70\% (12\%) used absorption (variable) cost-based pricing, and 18\% used "market-based or competitive" pricing. Economists have long criticized cost-based pricing, for several reasons (Oxenfeldt \& Baxter, 1961). This procedure uses historical or budgeted cost, rather than opportunity cost, and average variable cost, rather than marginal cost. Absorption costing includes average fixed cost which is normatively irrelevant to short-run pricing. The profit markup on cost does not explicitly incorporate information about demand.

Countering such criticism, justifications of costbased pricing invoke a decision-cost argument. Given limited knowledge about demand and opportunity cost, firms employ simplified procedures that economize on decision cost (Cyert \& March, 1992). When initial offers are subject to revision depending on the reactions of customers and competitors, cost-based pricing may be procedurally rational, i.e. economizing on decision cost, though not substantively rational, i.e. optimal without regard to decision cost (Simon, 1976). Accordingly, costing systems may 
play a role in explaining the disequilibrium process of price formation involving procedurally rational sellers, but no role in predicting equilibrium prices assuming substantively rational choice (Waller, 1995). In this regard, an important issue is whether alternative costing systems bias price offers in the market convergence process. Using models and methods from psychology, past accounting experiments have demonstrated cost-based pricing biases in individual settings, but none has examined whether such biases persist in markets.

Early experiments used the lens model from psychology to examine the sensitivity of sellers' pricing decisions to changes in costing systems (Ashton, 1976, 1981; Dyckman et al., 1982; Swieringa et al., 1979). Ashton (1976) had each seller set prices for 60 products using three cues, i.e. unit cost, demand elasticity, and competitor responsiveness. Absorption vs variable costing was manipulated on a within-subject basis after 30 prices had been set, with the order of systems varied over subjects. Sellers starting with variable (absorption) costing also were told that the change in systems resulted in less (more) useful information due to the inclusion (exclusion) of fixed cost. Two control groups used either absorption or variable costing for all 60 products. Ashton constructed a regression model of each seller's pricing policy over the first 30 products, and computed the mean absolute difference between actual and predicted prices for the last 30 products. This difference measured sensitivity to the change in costing systems, which was significantly higher for the experimental vs control groups. In a critique, Libby (1976) expressed concerns about the confounded manipulation of costing-system change and stated usefulness, and about differences in cost data for the experimental and control groups. Responding to these concerns, Swieringa et al. (1979) performed a replication, isolating the manipulation of costing-system change and holding constant the cost data over groups. Swieringa et al. (1979) found that sellers with a costing-system change adjusted their information processing more than the control groups did. In another replication using older subjects with more exposure to accounting, Dyckman et al. (1982) reported similar results.
Two experiments tested hypotheses from Lere (1986) about the effects of absorption vs variable costing on the correspondence between profitmaximizing decisions and cost-based offers made with a specific heuristic (see also Dickhaut \& Lere, 1983). The heuristic consisted of the following steps: (1) the seller suggests a price, $p$, to his accountant, (2) the accountant determines expected demand, $E[q(p)]$, and reports the unit cost, $c$, (3) the seller evaluates $c$ against $c^{*}=E$ $\left[p q^{\prime}(p)+q(p)\right] / E\left[q^{\prime}(p)\right]$, and (4) the process iterates until $c=c^{*}$. The degree to which the heuristic approximates profit maximization depends on absorption vs variable costing. ${ }^{2}$ In one experiment (Hilton et al., 1988), each subject chose between absorption and variable costing, and made a price offer after iterating with a simulated accountant for up to ten repetitions. Each seller knew the demand function (or probability distribution of demand functions) and type of cost function (linear vs nonlinear and stochastic vs deterministic). Sellers had monetary incentives and profit feedback after each trial. The results did not support Lere's hypotheses. Sellers' price offers differed significantly from prices under the assumed heuristic as well as from optimal prices, and most sellers chose absorption over variable costing under all conditions. Also, mean price offers were higher under absorption vs. variable costing under all conditions. In an experiment involving quantity decisions, Turner and Hilton (1989) similarly found significant divergences from optimum and a general preference for absorption costing.

The above experiments provided limited evidence regarding the role of absorption vs variable costing for pricing decisions in markets. The stream of lens-model studies beginning with Ashton (1976) examined pricing decisions in individual settings that lacked most of the distinctive features

\footnotetext{
${ }^{2}$ Lere's (1986) model made the following predictions. Given a linear, deterministic cost function, variable costing induces better prices, i.e. prices set by the heuristic are closer to optimal prices, than absorption costing does. Given a linear, stochastic cost function and deterministic demand, variable (absorption) costing induces better prices under risk neutrality (aversion). Given a nonlinear cost function, absorption costing always induces better prices.
} 
of markets discussed earlier. Despite many task repetitions, sellers had neither monetary incentives nor profit feedback. Although available information included cues about market conditions, there was no actual trade between sellers and buyers. The later studies (Hilton et al., 1988; Turner \& Hilton, 1989) added improvements such as formal models that recognized decision cost, monetary incentives, task repetitions (under changing conditions), and profit feedback. However, these studies assumed decision heuristics involving interaction between the seller and accountant, rather than interaction among sellers and buyers in markets. The studies also assumed that demand was known, at least as a probability distribution. All of the above studies involved one-shot offers with no chance of price revision or convergence, and none included actual seller competition or the threat of bankruptcy.

Although not concerned with absorption vs variable costing, Gupta and King (1996) examined cost-based decisions in a setting that built upon Hilton et al. (1988). Gupta and King (1996) manipulated cost-report accuracy and production complexity in a multiproduct firm. Each subject acted as a monopolist (i.e. no seller competition) who made cost forecasts for three products given imperfect cost reports. There was no explicit pricing decision. Instead, each subject's cost forecast together with a simulated demand function determined price, quantity, and profit. Also, there was no fixed or joint cost. Total variable cost depended on each product's requirements for material and resources in three conversion processes. The more accurate cost report was based on two conversion cost pools, while the less accurate report was based on only one. Each product in the more complex firm used resources nonproportionately in the conversion processes, while each product in the simpler firm used resources proportionately. Subjects went through 20 task repetitions under stable conditions, e.g. constant demand, with monetary incentives and feedback. As expected, the results showed higher profit given more accurate cost reports and a simpler firm. The results also revealed systematic learning whereby subjects revised their forecasts toward optimum, despite inaccurate cost reports. Learning from experience may be a procedurally rational substitute for costreport accuracy. As elaborated below, this study's experiment also involved the procedural rationality of seller learning given profit and market feedback.

\subsection{Hypotheses}

The experiment incorporated many features that, taken together, distinguish individual and market settings, e.g. monetary incentives, task repetitions, profit feedback, trading institution, seller competition, endogenous information about demand, and the threat of bankruptcy. The experiment produced evidence about four hypotheses.

The first hypothesis concerns market convergence. It was expected that sellers' price offers would converge toward optimum over each set of trading periods. Confirming this expectation was necessary to establish a general correspondence between this study's market setting and other laboratory markets. Competitive equilibrium predictions were based on market demand and supply, without regard to costing systems. There were four lenient markets in which demand tended to be relatively high (Fig. 1), and four harsh markets in which demand tended to be relatively low (Fig. 2). The reason for the between-market manipulation of demand was to vary the threat of bankruptcy faced by sellers. A seller went bankrupt when his cash balance (initial endowment \pm profit or loss) was negative, and suboptimal decisions were more likely to cause bankruptcy in the harsh markets. Each market used six demand functions corresponding to six sets of eight periods. The reason for the within-market manipulation of demand was to create recurrent disequilibrium states in which sellers were ignorant about demand. This allowed repeated observations of the convergence process. The supply function (see Figs. 1 and 2) was constructed by aggregating the sellers' marginal cost functions. For each set of a market, the optimal price and quantity (Table 1) were determined by the intersection of the supply function and relevant demand function. Seller performance was measured by price error, i.e. the absolute difference between a seller's price offer and the optimal price, where the latter depended on the set and 


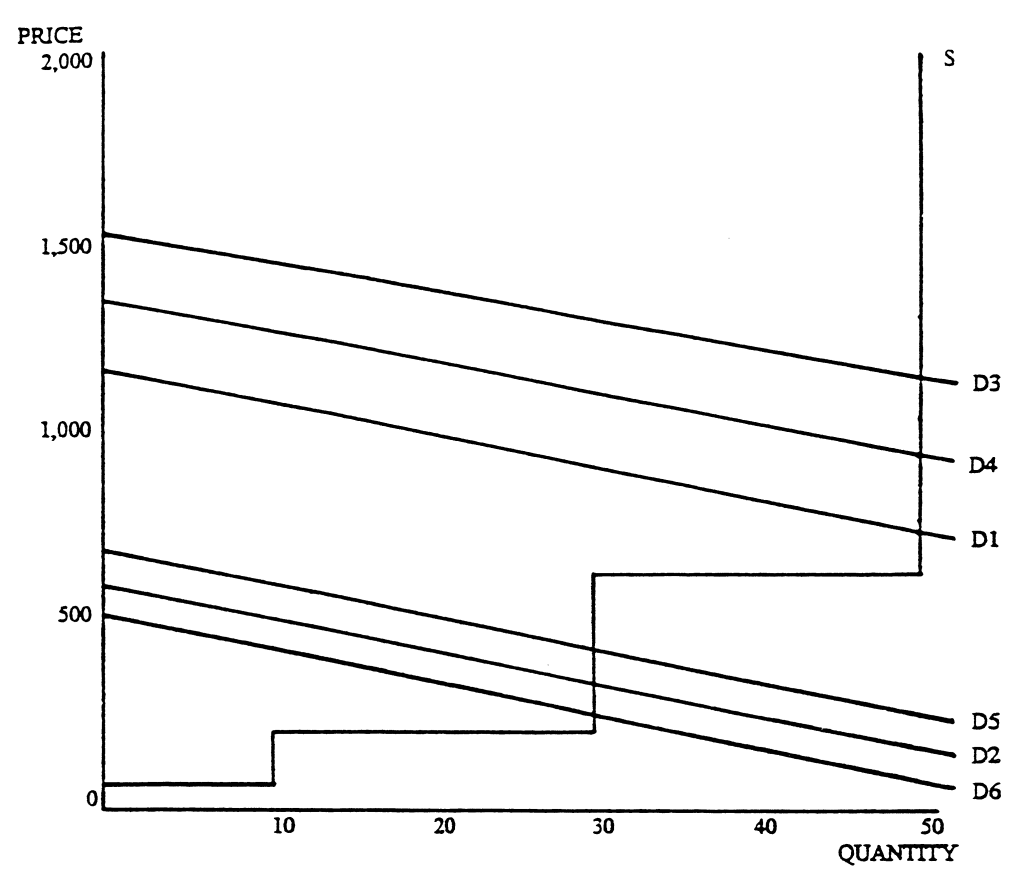

Fig. 1. Demand and supply for lenient markets.

market (Table 1). ${ }^{3}$ Consistent with convergence toward optimum, the first hypothesis is:

\section{H1. Sellers' price errors approach zero over periods 1-8 of a set.}

The second and main hypothesis concerns the persistence of a cost-based pricing bias in the market convergence process. Because of the market features discussed earlier, it was expected that a bias in price offers due to absorption vs variable costing would not persist. Assuming higher price offers under absorption costing in the initial period (comparable to the findings in individual settings), it was expected that sellers would respond to profit and market feedback by revising their price offers toward optimum without regard to unit-cost signals.

\footnotetext{
3 Absolute rather than signed differences were used, because analyses that aggregate over positive and negative differences would understate the average magnitude of deviations from optimum (cf. Bloomfield, 1997). Also, price offers converged toward optimum from above (positive differences) in some sets, but from below (negative differences) in other sets. Analyses that aggregate over sets would involve the same understatement problem.
}

Accordingly, the results should reveal an interactive effect for costing systems and periods, whereby price offers differ under absorption vs. variable costing in the early, but not later, periods of a set. ${ }^{4}$

\section{H2. A bias in price offers due to absorption vs variable costing does not persist over periods 1-8 of a set.}

The third hypothesis concerns seller learning. Consistent with the behavioral theory of the firm (Cyert \& March, 1992; Levitt \& March, 1988), seller learning may be viewed as the adaptation of current decisions to experiential feedback on past decisions. Sellers received two kinds of feedback, profit or loss from their own trades and observations of other trades. Profit feedback was measured by profit variance, i.e. the difference between a seller's actual and target profit last period. Target profit equaled a seller's markup times offered

4 Although sellers returned to a similar state of ignorance about demand in period 1 of each set, it is an open issue whether the same pattern of a cost-based pricing bias (i.e. its emergence and persistence or elimination) unfolds in each set. Task experience may affect the pattern in later sets (see Results). 


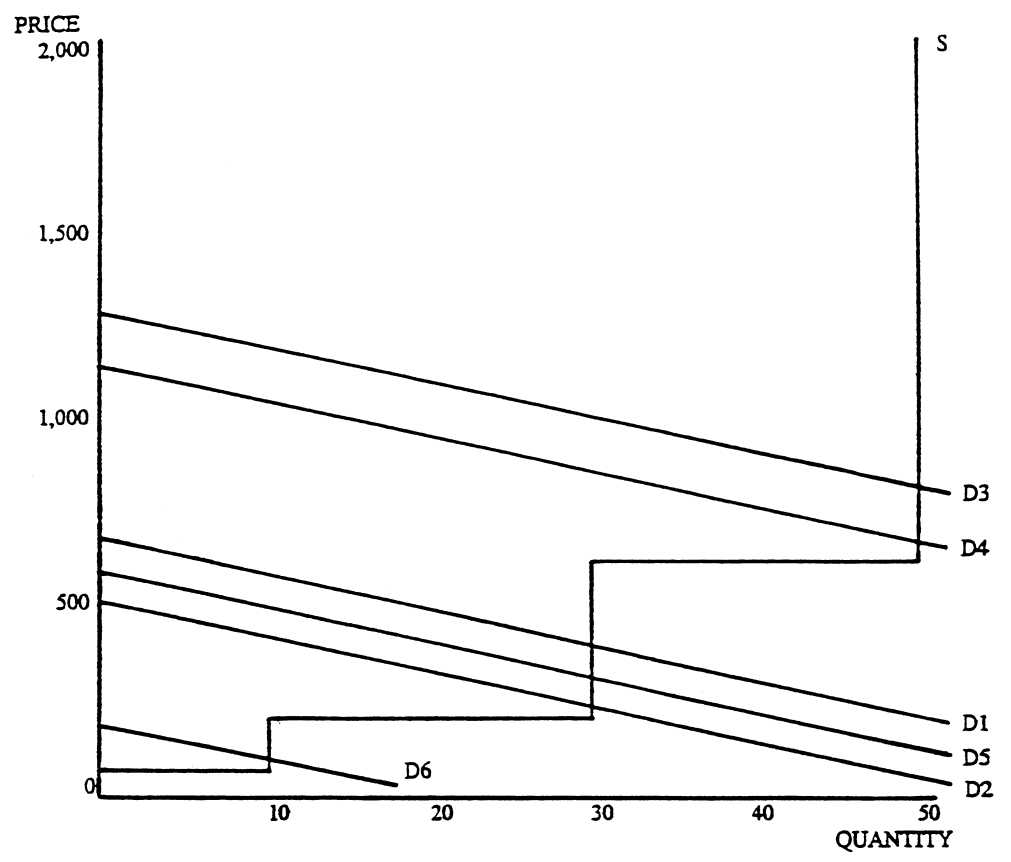

Fig. 2. Demand and supply for harsh markets.

quantity under absorption costing, or, markup times offered quantity minus fixed cost under variable costing. When a seller made a sale at the offered price and quantity, the profit variance was zero; otherwise, the profit variance was unfavorable. Market feedback was measured by price variance, i.e. the difference between a seller's price offer and the average price per unit sold last period. It was expected that profit and price variances would be correlated, but not perfectly. High price offers relative to competitors' were likely to result in both profit and price variances, whereas low price offers relative to competitors' were likely to result in a price variance but no profit variance. Seller learning was measured by price revision, i.e. the increase or decrease in a seller's price offer from $t$ to $t+1(t=1, \ldots, 7)$. It was expected that larger profit and price variances would induce larger price revisions.

\section{H3. Price revisions depend on feedback regarding profit and price variances.}

The last hypothesis concerns the threat of bankruptcy. Using lenient vs harsh markets as a proxy for the threat of bankruptcy, it was expected that sellers' price revisions would accelerate as the threat of bankruptcy increased. When comparing price revisions between the lenient vs harsh markets, however, a possible confound was that differences in optimal prices may have led to differences in total price revisions, regardless of the rate of price revisions. Accordingly, a second measure of learning, which used each seller as his own control, was relative price revision, i.e. the ratio of a seller's price revision from period $t$ to $t+1(t=1, \ldots, 7)$ over his total price revision from period 1 to 8 of a set. If a greater threat of bankruptcy causes faster price revision, then the results should reveal an interactive effect for markets and periods, whereby relative price revision is higher in the harsh vs. lenient markets in the early periods of a set. ${ }^{5}$

\section{H4. A greater threat of bankruptcy increases rela- tive price revision in the early periods of a set.}

\footnotetext{
${ }^{5}$ By construction, each subject's relative price revision sums to one over a set of periods. If relative price revision is higher in the harsh markets for early periods (H4), then the measure must be higher in the lenient markets for later periods.
} 
Table 1

Optimal prices, quantities, and profit (per seller)

\begin{tabular}{lrrr}
\hline $\begin{array}{l}\text { Demand } \\
\text { A. Lenient markets }\end{array}$ & Price & Quantity & Profit \\
\hline D1 & & & \\
D2 & 755 & 5 & 265 \\
D3 & 315 & 3 & $-1,265$ \\
D4 & 1,155 & 5 & 2,265 \\
D5 & 955 & 5 & 1,265 \\
D6 & 415 & 3 & -965 \\
Average & 215 & 3 & $-1,565$ \\
B. Harsh markets & 635 & 4 & 0 \\
D1 & & & \\
D2 & 395 & 3 & -1.025 \\
D3 & 195 & 3 & $-1,625$ \\
D4 & 855 & 5 & 765 \\
D5 & 705 & 5 & 15 \\
D6 & 295 & 3 & $-1,325$ \\
\hline Average & 65 & 1 & $-1,825$ \\
\hline
\end{tabular}

\section{Method}

The procedure for the lenient markets is described first, followed by differences for the harsh markets. In each trading period, ten sellers (undergraduate business students) made offers to sell a product. As a buffer against possible loss, each seller received an initial endowment of 50,000 francs, the experimental currency. Making an offer consisted of stating the maximum quantity for sale between one and five units, referring to a schedule showing the unit cost at each quantity, and adjusting the unit cost for target profit. The schedule was prepared under absorption costing for five sellers and under variable costing for five sellers, holding constant the true cost function. ${ }^{6}$ The unit cost under absorption costing was 1890,1025 , 737, 715 and 702 francs, for one to five units, respectively; the corresponding numbers under variable costing were $30,95,117,250$ and 330

\footnotetext{
${ }^{6}$ The true cost function was a fixed cost of 1860 francs, and a marginal cost of 30 francs for the first unit sold, 160 francs for the second and third units sold, and 650 francs for the fourth and fifth units sold. Relatively large steps in the cost function were used to ensure nontrivial differences in optimal prices among alternative demand levels in each market (Figs. 1 and 2 and Table 1 ).
}

francs. There were 48 periods, split into six sets of eight. Buyers were simulated with a computer program executing the demand functions in Figs. 1 and $2 .{ }^{7}$ Demand was constant for each set, but varied over sets. Specifically, D1 in Fig. 1 was employed for set 1, D2 for set 2, and so on. Periodic profit or loss equalled the offered price times units sold minus total variable and fixed cost. Variable cost depended on units sold, but fixed cost was unavoidable. A bankruptcy occurred when a seller's franc balance was negative. At the end of the experiment, each seller's franc balance was translated into the probability of winning $\$ 20$ in a lottery, at a rate of $1 / 100,000$. This payoff structure provided a control for risk preference, in that a seller who maximized the expected probability of winning the cash prize was risk-neutral as to francs when making sales offers (Davis \& Holt, 1993). Cost and demand parameters were specified such that optimal prices and quantities implied zero profit on average (Table 1). The expected probability of winning the prize was 0.50 $(50,000 / 100,000)$, and expected pay was $\$ 25$ $(0.50 \times \$ 20+\$ 15$ for participating $)$.

To ensure consistency over markets, the instructions were presented to sellers by playing a pre-recorded tape. The speaker on the tape read the instructions aloud, while sellers read along in a booklet. The appendix contains the instructions and offer sheet for sellers with absorption costing. The instructions and offer sheet for sellers with variable costing were identical, except for the cost schedule. The instructions described the market setting in detail: the trading institution, task of making offers, sequence of events in a period, initial endowment and payoff structure, general nature of demand and timing of random shifts, limits on unit sales, profit computation, periodic fixed cost and variable cost, cost schedule, price limits (0-2000 francs), and bankruptcy rule.

\footnotetext{
7 To illustrate, D1 in Fig. 1 implied that buyers were willing to acquire one unit at a price of 1245 francs, two units at 1235 francs, three units at 1225 francs, four units at 1215 francs, ..., and 50 units at 755 francs. Suppose that two sellers each offered to sell two units, but at different prices, i.e. 1210 francs (seller A) and 1220 francs (seller B). The trades would be two units at 1210 francs for seller A and one unit at 1220 francs for seller B.
} 
After reading the instructions, sellers were shown four examples covering various possible sales offers and demand conditions. For simplicity, each example included only two sellers, but gave detailed explanations for completing offer sheets and interpreting feedback. Example 1 was a case in which the sellers offered different prices and quantities, and buyers accepted both offers. Example 2 repeated the offers of Example 1, but demand was lower such that only one seller made a sale. Example 3 was a case in which the sellers offered the same price, but demand was not sufficient for each to sell the offered quantities. When sellers offered the same price, the number of units sold were divided as evenly as possible. When an even distribution was not possible, the remaining unit(s) was allocated randomly. Example 4 was a case in which a seller went bankrupt. The examples were prepared under absorption costing for five subjects and variable costing for five subjects. The speaker on the tape did not refer to specific values of cost or markups. All subjects heard the same description of the market procedure.

In each period, sellers had 3 min to complete the offer sheet, after which the sheets were collected and the offers were entered into a computer. Periodic feedback consisted of two parts. One part was market activity (i.e. price and quantity for each sale) which was displayed publicly on large screens. Another screen displayed publicly the number of surviving sellers, which was updated when a bankruptcy occurred. The other part was each seller's results (i.e. the price and quantity for a sale, revenue, total cost, profit or loss, and beginning and ending franc balances) which were displayed privately on a terminal. These displays continued until the offers for the next period were entered. To ensure that sellers paid attention to both types of feedback, there was a 20 -s lag between initiation of the public display of market results and private display of each seller's results.

This procedure was repeated for 48 periods. The entire experiment, including the instructions, lasted approximately $2.5 \mathrm{~h}$. At the end, the lottery was played separately for each seller with a positive franc balance, who was paid according to the above description.
The harsh markets followed the same procedure, with one exception. ${ }^{8}$ Because of the difference in profit opportunities, the cash prize was raised to $\$ 100$ in order to equate expected pay for all markets. Given optimal behavior in the harsh markets (Table 1), each seller's ending franc balance would be 9840 francs $(50,000-48 \times 836.66)$. The expected probability of winning the prize was. 10 $(9,840 / 100,000)$, and expected pay was $\$ 25$ $(0.10 \times \$ 100+\$ 15)$. This procedure held expected pay constant at $\$ 25$ for the lenient and harsh markets.

\section{Results}

\subsection{Convergence toward optimum}

H1 predicted that sellers' price errors approach zero over periods $1-8$ of a set. Table 2 reports descriptive statistics regarding seller and market performance by set and period, separately for the lenient and harsh markets. ${ }^{9}$ The first column shows medians for price error over sellers; e.g., in period 1 of set 1 , the median price error was 245 (628) francs, relative to the optimal price of 755 (395) francs, for the 40 sellers in the lenient (harsh) markets. Changes in median price errors from period 1-8 show a clear pattern of convergence toward optimum. Averaging over sets for the

\footnotetext{
${ }^{8}$ In two of the harsh markets, the number of periods was allowed to exceed 48 (to at most 51), in order to achieve a minimum bankruptcy rate of $4 / 10$. The intent was to observe whether bankruptcies were related to costing systems. There were 22 survivers in the harsh markets after all periods; 13 were assigned absorption costing and 9 were assigned variable costing $\left(\chi^{2}=1.62, p>0.10\right)$. To facilitate comparisons between markets, the Results section analyzes the data for periods $1-48$ only.

9 All laboratory-market studies with multiple trading periods share the problem of serial dependence among observations over time. Indeed, $\mathrm{H} 1$ predicts a particular pattern of serial dependence. The approach taken here is to present the results on a disaggregated basis and, as appropriate, present additional aggregate tests. The disaggregated analyses were not intended as independent hypothesis tests. Repeated-measures analysis of variance was used in the aggregate tests, with set and period as within-subject factors. These tests accommodated serial dependence by assessing the effects of each within-subject factor, and between-subjects factors, with respect to distinct error terms (Neter, Kutner, Nachtsheim \& Wasserman, 1996).
} 
Table 2

Seller and market performance ${ }^{\mathrm{a}}$

\begin{tabular}{|c|c|c|c|c|c|}
\hline \multirow[b]{2}{*}{ Set-period } & \multicolumn{3}{|c|}{ Seller performance } & \multicolumn{2}{|l|}{ Market performance } \\
\hline & Price error & Quantity error & Profit error & No. of trades/ no. of sellers & Efficiency \\
\hline $1-1$ & $245(628)$ & $2(1)$ & $755(835)$ & $24 / 40(4 / 40)$ & $69 \%(10 \%)$ \\
\hline $1-2$ & $153(348)$ & $.5(1)$ & $725(835)$ & $28 / 40(11 / 40)$ & $81(45)$ \\
\hline $1-3$ & 145 (127) & $0(1)$ & $475(655)$ & $32 / 40(21 / 40)$ & $89(72)$ \\
\hline $1-4$ & $117(105)$ & $0(0)$ & $475(217)$ & $34 / 40(25 / 40)$ & $93(77)$ \\
\hline $1-5$ & $105(72)$ & $0(0)$ & $507(360)$ & $31 / 40(23 / 40)$ & $93(80)$ \\
\hline $1-6$ & $98 \quad(75)$ & $0(0)$ & $475(235)$ & $34 / 40(26 / 40)$ & $94(82)$ \\
\hline $1-7$ & $96 \quad(72)$ & $0(0)$ & $445(225)$ & $34 / 40(27 / 40)$ & $94(84)$ \\
\hline $1-8$ & $89 \quad(62)$ & $0(.5)$ & $392(216)$ & $35 / 40(28 / 40)$ & $96(86)$ \\
\hline $2-1$ & $486(455)$ & $2(0)$ & $595(235)$ & $1 / 40 \quad(7 / 40)$ & $0(26)$ \\
\hline $2-2$ & $395(248)$ & $2(0)$ & $595(235)$ & $6 / 40(12 / 40)$ & $27(26)$ \\
\hline $2-3$ & $207(202)$ & $2(0)$ & $595(235)$ & $14 / 40(15 / 40)$ & $58(65)$ \\
\hline $2-4$ & $160(155)$ & $1(0)$ & $595(235)$ & $17 / 40(19 / 40)$ & $68(76)$ \\
\hline $2-5$ & $110(135)$ & $1(0)$ & $545 \quad(235$ & $20 / 40(23 / 40)$ & $80(81)$ \\
\hline $2-6$ & $83(123)$ & $.5(0)$ & $241(291)$ & $28 / 40(25 / 40)$ & $84(83)$ \\
\hline $2-7$ & $59(110)$ & $0(0)$ & 257 (236) & $31 / 40(29 / 40)$ & $88(86)$ \\
\hline $2-8$ & $46(100)$ & $0(0)$ & $193(235)$ & $31 / 40(31 / 40)$ & $87(88)$ \\
\hline $3-1$ & $411(405)$ & $0(2)$ & $2,180(1,827)$ & $35 / 40(37 / 40)$ & $89(86)$ \\
\hline $3-2$ & 255 (108) & $0(0)$ & $1,275(649)$ & $38 / 40(36 / 40)$ & $96(92)$ \\
\hline $3-3$ & $194 \quad(55)$ & $0(0)$ & $1,025(280)$ & $38 / 40(36 / 40)$ & $95(95)$ \\
\hline $3-4$ & $145 \quad(44)$ & $0(0)$ & $775(216)$ & $38 / 40(38 / 40)$ & $98(96)$ \\
\hline $3-5$ & 104 (44) & $0(0)$ & $537(210)$ & $37 / 40(35 / 40)$ & $95(96)$ \\
\hline $3-6$ & $94 \quad(54)$ & $0(0)$ & $475(270)$ & $40 / 40(36 / 40)$ & $97(95)$ \\
\hline $3-7$ & $63 \quad(75)$ & $0(0)$ & $360(370)$ & $38 / 40(35 / 40)$ & 99 (94) \\
\hline $3-8$ & $55 \quad(73)$ & $0(0)$ & $302(322)$ & $36 / 40(36 / 40)$ & $94(94)$ \\
\hline $4-1$ & 205 (99) & $0(0)$ & $1,025(497)$ & $37 / 40(31 / 40)$ & $91(91)$ \\
\hline $4-2$ & $86 \quad(5)$ & $0(0)$ & $462(415)$ & $38 / 40(33 / 40)$ & $98(95)$ \\
\hline $4-3$ & $50(110)$ & $0(0)$ & $275(537)$ & $37 / 40(34 / 40)$ & $96(96)$ \\
\hline $4-4$ & 45 (114) & $0(0)$ & $225(550)$ & $37 / 40(37 / 40)$ & $95(96)$ \\
\hline $4-5$ & $43 \quad(96)$ & $0(0)$ & $222 \quad(47)$ & $38 / 40(35 / 40)$ & $96(96)$ \\
\hline $4-6$ & 42 (93) & $0(0)$ & $210(517)$ & $38 / 40(34 / 40)$ & $96(97)$ \\
\hline $4-7$ & $42 \quad(81)$ & $0(0)$ & $212(462)$ & $38 / 40(35 / 40)$ & $96(97)$ \\
\hline $4-8$ & $35 \quad(57)$ & $0(0)$ & $165(285)$ & $39 / 40(35 / 40)$ & 97 (98) \\
\hline $5-1$ & $335(425)$ & $2(2)$ & $895(235)$ & $4 / 40 \quad(4 / 40)$ & $10(17)$ \\
\hline $5-2$ & $185(155)$ & $1(0)$ & 725 (235) & $20 / 40(22 / 40)$ & $54(66)$ \\
\hline $5-3$ & $79(105)$ & $0(0)$ & $375(366)$ & $25 / 40(26 / 40)$ & $81(80)$ \\
\hline $5-4$ & $35 \quad(77)$ & $0(0)$ & $157(390)$ & $29 / 40(29 / 40)$ & $92(86)$ \\
\hline $5-5$ & $16 \quad(54)$ & $0(0)$ & $228(415)$ & $33 / 40(32 / 40)$ & $95(90)$ \\
\hline $5-6$ & 15 (44) & $0(0)$ & $91(414)$ & $35 / 40(34 / 40)$ & $97(92)$ \\
\hline $5-7$ & $13 \quad(35)$ & $0(0)$ & 43 (373) & $36 / 40(35 / 40)$ & $97(93)$ \\
\hline $5-8$ & 12 (27) & $0(0)$ & $43(358)$ & $39 / 40(36 / 40)$ & 97 (94) \\
\hline $6-1$ & $586(645)$ & $2(4)$ & $295 \quad(35)$ & $1 / 40 \quad(0 / 40)$ & $0 \quad(0)$ \\
\hline $6-2$ & $235(335)$ & $0(2)$ & $295 \quad(35)$ & $15 / 40 \quad(1 / 40)$ & $50 \quad(0)$ \\
\hline $6-3$ & $160(165)$ & $0(2)$ & $295 \quad(35)$ & $20 / 40 \quad(6 / 39)$ & $71(29)$ \\
\hline $6-4$ & 112 (57) & $0(1)$ & $295 \quad(35)$ & $26 / 40(15 / 38)$ & $84(73)$ \\
\hline $6-5$ & $88 \quad(30)$ & $0(0)$ & $268 \quad(35)$ & $28 / 40(23 / 38)$ & $87(84)$ \\
\hline $6-6$ & $81 \quad(20)$ & $0(0)$ & $244 \quad(23)$ & $31 / 40(27 / 38)$ & $90(87)$ \\
\hline $6-7$ & $65 \quad(15)$ & $0(0)$ & $193 \quad(15)$ & $32 / 40(29 / 33)$ & $91(91)$ \\
\hline $6-8$ & $59 \quad(15)$ & $0(0)$ & $165 \quad(15)$ & $34 / 40(23 / 31)$ & $93(90)$ \\
\hline
\end{tabular}

${ }^{a}$ The first (second) entry in each cell pertains to the lenient (harsh) markets. Entries in the first through third columns are medians over sellers for price error, quantity error, and profit error, respectively. Entries in the fourth column are frequencies of sellers with trades. Entries in the fifth column are medians over markets for efficiency. 
lenient (harsh) markets, the median price error decreased by $85 \%(81 \%)$ from periods 1 to 8 . For each set, a Wilcoxon sign test was used to compare the price errors in period 1 and 8, separately for the lenient and harsh markets; in each case, the decrease was highly significant $(p<0.001)$. As an aggregate test, a repeated-measures analysis of variance (ANOVA) was performed using $\mathrm{LN}$ (price error) as the dependent measure, with sets (1-5) and periods (1-8) as within-subjects factors, and lenient vs harsh markets and absorption vs variable costing as between-subjects factors. Excluding set 6 avoided the problem of missing values due to bankruptcies. ${ }^{10}$ Using logged price offers as the dependent variable reduced the inordinate effects of unusually high or low offers. The first column of Table 3 shows the main and interactive effects (results in other columns are discussed later). The relevant result for $\mathrm{H} 1$ was the significant effect of periods $(F=254.96, p<0.001)$. Consistent with the convergence pattern in the first column of Table 2, the mean of LN (price error) decreased monotonically from period 1 to 8 . These results support $\mathrm{H} 1$.

Table 3 shows other significant effects for LN (price error), including sets $(F=86.43, p<0.001)$, markets $(F=9.60, p<0.003)$, periods $\times$ markets $(F=7.39$, $p<0.001), \quad$ sets $\times$ markets $\quad(F=29.10, p<0.001)$, periods $\times$ sets $(F=13.16, p<0.001)$, and periods $\times$ markets $\times$ sets $(F=11.52, p<0.001)$. The mean of LN (price error) decreased from set 1 to 5, which may be attributed to task experience and changing demand conditions. The mean generally was higher for harsh vs lenient markets, and the difference was larger in later periods. The market effect also varied over sets. The mean was higher for harsh (lenient) markets in sets 2 and 4 ( 3 and 5), and about the same in set 1 . In all sets and markets, the mean decreased over periods, but at somewhat different rates. ${ }^{11}$

In addition to price errors, Table 2 provides descriptive statistics on other measures of seller and market performance. The second and third

\footnotetext{
${ }^{10}$ As expected, some sellers in the harsh markets went bankrupt, beginning in period 3 of set 6 ; nine sellers went bankrupt by period 8 of set 6 .

11 As to the interactive effect of periods $\times$ markets $\times$ sets, the mean of LN (price error) was higher for the harsh (lenient) markets in later periods of sets 2 and 4 (1); the mean was higher for the harsh (lenient) markets in most periods of set 3 (5).
}

columns show the median quantity errors and profit errors, respectively. A quantity error was defined as the absolute difference between a seller's quantity offer and the optimal quantity, and a profit error as the absolute difference between a seller's actual and optimal profit, where the optimal values depended on the set and market (Table 1). The fourth column shows the number of trades divided by the number of participating sellers. The last column shows the median efficiency over markets. Efficiency increased toward $100 \%$ as the total quantity sold increased toward optimum, but at a decreasing rate because buyers' marginal value was decreasing and sellers' marginal cost was increasing. ${ }^{12}$ Generally, these measures were consistent with the decrease in price errors over periods. In most sets and markets, median quantity errors quickly decreased to zero, median profit errors decreased over periods, and both the percentage of sellers with trades and market efficiency approached $100 \% .^{13}$ These convergence results are comparable to many laboratory-market studies.

\footnotetext{
12 To illustrate, the demand function for set 1 of the lenient markets implied that buyers valued the first unit at 1245 francs, second unit at 1235 francs, third unit at 1225 francs, ..., and 50th unit at 755 francs. Given the optimal quantity of 50 units, the aggregate value to buyers was 50,000 francs, and the aggregate variable cost to sellers was 16,500 francs $(10 \times 30+20 \times 160+$ $20 \times 650$ ), so that maximum profit was 33,500 francs. Suppose that three units were sold by different sellers (at any prices between 30 and 1225 francs), resulting in aggregate profit of 3615 francs $(1245+1235+1225-30 \times 3)$. In this case, efficiency would be $11 \%$ $(3,615 / 33,500)$.

13 There were some exceptions to the general convergence pattern. Regarding profit errors, there was minimal convergence in sets 2, 5, and 6 of the harsh markets, which may be attributed to the relatively small change in profit when a sale was made vs no sale. In set 6 of the harsh markets, for example, no sale implied a profit of $-1,860$ francs, compared to optimal profit of -1825 francs assuming the sale of one unit at 65 francs. Regarding the percentage of sellers with trades, the pattern was different for sets 3 and 4, compared to the other sets, in that the percentage started and stayed high. Figs. 1 and 2 show a large upward shift in demand from set 2 to 3 , and a small downward shift from set 3 to 4 . Although sellers knew that shifts in demand were random, prices in period 8 of a set apparently affected offers in period 1 of the next set. Such carryover effects explain why there were more trades from the start in sets 3 and 4 .
} 
Table 3

Analyses of variance for price errors, offers, and relative price revision $^{\mathrm{a}}$

\begin{tabular}{lccc}
\hline & $\begin{array}{l}\text { LN } \\
\text { (price error) }\end{array}$ & $\begin{array}{l}\text { LN } \\
\text { (price offer) }\end{array}$ & $\begin{array}{l}\text { Relative } \\
\text { price revision }\end{array}$ \\
\hline Within-subjects effects: & & \\
$\mathrm{P}$ & $254.96(.001)$ & $53.69(.001)$ & $374.99(.001)$ \\
$\mathrm{P} \times \mathrm{M}$ & $7.39(.001)$ & $1.43(.19)$ & $12.85(.001)$ \\
$\mathrm{P} \times \mathrm{CS}$ & $0.54(.80)$ & $2.03(.05)$ & $0.22(.97)$ \\
$\mathrm{P} \times \mathrm{M} \times \mathrm{CS}$ & $0.94(.47)$ & $0.69(.68)$ & $0.73(.63)$ \\
$\mathrm{S}$ & $86.43(.001)$ & $1,154.22(.001)$ & - \\
$\mathrm{S} \times \mathrm{M}$ & $29.10(.001)$ & $29.51(.001)$ & - \\
$\mathrm{S} \times \mathrm{CS}$ & $1.02(.39)$ & $1.06(.38)$ & - \\
$\mathrm{S} \times \mathrm{M} \times \mathrm{CS}$ & $1.39(.24)$ & $1.17(.33)$ & - \\
$\mathrm{P} \times \mathrm{S}$ & $13.16(.001)$ & $67.68(.001)$ & $3.39(.001)$ \\
$\mathrm{P} \times \mathrm{S} \times \mathrm{M}$ & $11.52(.001)$ & $8.35(.001)$ & $2.85(.001)$ \\
$\mathrm{P} \times \mathrm{S} \times \mathrm{CS}$ & $0.74(.84)$ & $1.14(.28)$ & $1.31(.14)$ \\
$\mathrm{P} \times \mathrm{S} \times \mathrm{M} \times \mathrm{CS}$ & $0.78(.78)$ & $1.02(.44)$ & $0.65(.90)$ \\
Between-subjects & effects: & & \\
$\mathrm{M}$ & $9.60(.003)$ & $409.46(.001)$ & - \\
$\mathrm{CS}$ & $0.02(.87)$ & $1.20(.28)$ & - \\
$\mathrm{M} \times \mathrm{CS}$ & $1.13(.29)$ & $1.66(.20)$ & - \\
\hline
\end{tabular}

a P-stands for periods; S-for sets; M-for harsh vs lenient markets, and CS for absorption vs variable costing systems. Entries are F statistics with significance levels in parentheses.

\subsection{Effects of costing systems}

$\mathrm{H} 2$ predicted that a bias in price offers due to absorption vs variable costing does not persist over periods 1 to 8 of a set. Table 4 reports an ANOVA for each period using LN (price offer) as the dependent variable, with absorption vs variable costing and lenient vs harsh markets as between-subjects factors. The first and second columns indicate whether the mean of LN (price offer) was higher for absorption vs variable costing, and for lenient vs harsh markets, respectively. The number of observations was 80 (10 sellers $\times 8$ markets) in each ANOVA, except for periods 3-8 of set 6 , which omitted bankrupt sellers. Focusing on set 1 , costing systems had a significant effect in period $1(F=8.88, p<0.004)$; the mean (median) price offer was 1162 (1048) francs under absorption costing vs 933 (968) francs under variable costing. The higher unit cost under absorption costing apparently caused higher price offers, when sellers had not yet observed actual trades and were ignorant about demand. In period 2, the mean (median) price offer was 908 (877) francs under absorption costing vs 836 (772) francs under variable costing. Although price offers were still higher under absorption costing, the effect of costing systems was no longer significant. In periods $3-8$, price offers under absorption vs. variable costing were about the same. In contrast, harsh vs lenient markets had an insignificant effect in period 1, but highly significant effects in the remaining periods. $R^{2}$ increased from 0.11 in period 1 to 0.97 in period 8 , due to the increasingly strong effects of markets and decreasing variation in price offers. The results for set 1 support $\mathrm{H} 2$. The initially observed bias did not persist, but instead was overwhelmed by demand conditions as revealed through actual trades.

The results for sets $2-6$ showed a similar pattern of weak effects due to costing systems, strong effects due to markets, and increasing $R^{2}$ over periods. Unlike set 1 , however, there was only a small cost-based pricing bias in period 1 of the subsequent sets (Table 4). Although the mean value of $\mathrm{LN}$ (price offer) was higher under absorption costing in period 1 of each set, costing systems had no significant effect. This result may be attributed to the combination of three factors. First, variation in price offers was relatively high in period 1 of each set, which lowered the likelihood of detecting of a significant bias. Second, despite the random shifts in demand over sets, prices in period 8 of a set often affected offers in period 1 of the next set (see note 13). Such carryover effects would mitigate a cost-based pricing bias. Third, some sellers learned during set 1 that their costing system was of limited usefulness, and placed less reliance on unit-cost signals in subsequent sets.

As an aggregate test, an ANOVA was performed using $\mathrm{LN}$ (price offer) as the dependent variable, with periods (1-8) and sets (1-5) as within-subjects factors, and absorption vs variable costing and lenient vs harsh markets as betweensubjects factors. The second column of Table 3 shows the main and interactive effects. Consistent with the above results, there was an insignificant effect for costing systems $(F=1.20, p>0.28)$, and a significant effect for markets $(F=409.46$, $p<0.001)$. The significant effects for sets 
Table 4

Analyses of variance for LN (price offer) ${ }^{\mathrm{a}}$

\begin{tabular}{|c|c|c|c|c|c|c|}
\hline \multirow[b]{2}{*}{ Set-period } & \multicolumn{2}{|c|}{ Group with higher LN (price offer) } & \multirow[b]{2}{*}{$\begin{array}{l}\text { Costing } \\
\text { systems }\end{array}$} & \multicolumn{2}{|c|}{ Main and interactive effects } & \multirow[b]{2}{*}{$R^{2}$} \\
\hline & $\begin{array}{l}\text { Absorption (A) } \\
\text { vs. variable (V) }\end{array}$ & $\begin{array}{l}\text { Lenient }(\mathrm{L}) \\
\text { vs harsh }(\mathrm{H})\end{array}$ & & Markets & $\begin{array}{l}\text { Costing systems } \\
\times \text { markets }\end{array}$ & \\
\hline $1-1$ & A & $\mathrm{L}$ & $8.88(0.004)$ & $0.31(.58)$ & $1.63(0.21)$ & 0.11 \\
\hline $1-2$ & A & $\mathrm{L}$ & $1.63(0.21)$ & $11.68(0.001)$ & $0.01(.91)$ & 0.15 \\
\hline $1-3$ & $\mathrm{~V}$ & $\mathrm{~L}$ & $0.17(0.68)$ & $74.99(0.001)$ & $0.45(0.51)$ & 0.49 \\
\hline $1-4$ & $\mathrm{~V}$ & $\mathrm{~L}$ & $0.74(0.39)$ & $107.61(0.001)$ & $0.03(0.86)$ & 0.59 \\
\hline $1-5$ & $\mathrm{~V}$ & $\mathrm{~L}$ & $0.85(0.36)$ & $140.77(0.001)$ & $4.52(0.037)$ & 0.64 \\
\hline $1-6$ & A & $\mathrm{L}$ & $0.12(0.73)$ & $418.03(0.001)$ & $2.15(0.15)$ & 0.84 \\
\hline $1-7$ & $\mathrm{~V}$ & $\mathrm{~L}$ & $0.17(0.68)$ & $309.30(0.001)$ & $0.20(0.66)$ & 0.80 \\
\hline $1-8$ & A & $\mathrm{L}$ & $0.21(0.65)$ & $2,395.89(0.001)$ & $0.30(0.59)$ & 0.97 \\
\hline $2-1$ & $\mathrm{~A}$ & $\mathrm{~L}$ & $1.83(0.18)$ & $14.46(0.001)$ & $2.03(0.16)$ & 0.17 \\
\hline $2-2$ & $\mathrm{~V}$ & $\mathrm{~L}$ & $0.02(0.89)$ & $41.74(0.001)$ & $0.04(0.84)$ & 0.35 \\
\hline $2-3$ & $\mathrm{~V}$ & $\mathrm{~L}$ & $0.09(0.77)$ & $1.40(0.24)$ & $1.49(0.23)$ & 0.02 \\
\hline $2-4$ & A & $\mathrm{L}$ & $0.95(0.33)$ & $15.70(0.001)$ & $0.09(0.77)$ & 0.18 \\
\hline $2-5$ & A & $\mathrm{L}$ & $2.70(0.10)$ & $48.14(0.001)$ & $0.01(0.91)$ & 0.40 \\
\hline $2-6$ & A & $\mathrm{L}$ & $0.03(0.86)$ & $45.19(0.001)$ & $0.01(0.95)$ & 0.37 \\
\hline $2-7$ & A & $\mathrm{L}$ & $0.31(0.58)$ & $105.12(0.001)$ & $0.31(0.58)$ & 0.58 \\
\hline $2-8$ & $\mathrm{~A}$ & $\mathrm{~L}$ & $0.05(0.83)$ & $133.88(0.001)$ & $3.69(0.06)$ & 0.63 \\
\hline $3-1$ & A & $\mathrm{L}$ & $0.01(0.93)$ & $34.15(0.001)$ & $0.05(0.83)$ & 0.31 \\
\hline $3-2$ & $\mathrm{~A}$ & $\mathrm{~L}$ & $0.02(0.90)$ & $20.22(0.001)$ & $0.06(0.81)$ & 0.21 \\
\hline $3-3$ & $\mathrm{~V}$ & $\mathrm{~L}$ & $4.03(0.048)$ & $58.25(0.001)$ & $0.53(0.47)$ & 0.45 \\
\hline $3-4$ & A & $\mathrm{L}$ & $0.19(0.66)$ & $84.74(0.001)$ & $0.24(0.62)$ & 0.53 \\
\hline $3-5$ & $\mathrm{~V}$ & $\mathrm{~L}$ & $0.43(0.51)$ & $33.20(0.001)$ & $0.36(0.55)$ & 0.31 \\
\hline $3-6$ & $\mathrm{~V}$ & $\mathrm{~L}$ & $0.02(0.89)$ & $127.80(0.001)$ & $0.26(0.61)$ & 0.63 \\
\hline $3-7$ & A & $\mathrm{L}$ & $0.05(0.83)$ & $182.37(0.001)$ & $0.10(0.76)$ & 0.71 \\
\hline $3-8$ & $\mathrm{~V}$ & $\mathrm{~L}$ & $0.26(0.61)$ & $71.55(0.001)$ & $1.92(0.17)$ & 0.48 \\
\hline $4-1$ & A & $\mathrm{L}$ & $0.01(0.97)$ & $1.00(0.32)$ & $0.51(0.48)$ & 0.01 \\
\hline $4-2$ & A & $\mathrm{L}$ & $0.37(0.55)$ & $23.96(0.001)$ & $0.15(0.70)$ & 0.24 \\
\hline $4-3$ & A & $\mathrm{L}$ & $0.01(0.97)$ & $133.22(0.001)$ & $0.07(0.79)$ & 0.64 \\
\hline $4-4$ & $\mathrm{~V}$ & $\mathrm{~L}$ & $2.67(0.11)$ & $99.35(0.001)$ & $2.99(0.088)$ & 0.56 \\
\hline $4-5$ & A & $\mathrm{L}$ & $0.13(0.72)$ & $554.63(0.001)$ & $0.49(0.48)$ & 0.88 \\
\hline $4-6$ & A & $\mathrm{L}$ & $0.01(0.91)$ & $879.31(0.001)$ & $0.01(0.95)$ & 0.92 \\
\hline $4-7$ & A & $\mathrm{L}$ & $0.08(0.78)$ & $1,153.29(0.001)$ & $0.06(0.81)$ & 0.94 \\
\hline $4-8$ & $\mathrm{~V}$ & $\mathrm{~L}$ & $0.18(0.67)$ & $1,408.03(0.001)$ & $0.16(0.69)$ & 0.95 \\
\hline $5-1$ & A & $\mathrm{L}$ & $1.10(0.30)$ & $0.15(0.70)$ & $0.66(0.42)$ & 0.02 \\
\hline $5-2$ & $\mathrm{~A}$ & $\mathrm{~L}$ & $0.12(0.73)$ & $21.24(0.001)$ & $0.12(0.73)$ & 0.22 \\
\hline $5-3$ & A & $\mathrm{L}$ & $1.50(0.22)$ & $48.25(0.001)$ & $0.03(0.87)$ & 0.40 \\
\hline $5-4$ & A & $\mathrm{L}$ & $1.13(0.29)$ & $152.46(0.001)$ & $1.81(0.18)$ & 0.66 \\
\hline $5-5$ & $\mathrm{~V}$ & $\mathrm{~L}$ & $0.42(0.52)$ & $273.79(0.001)$ & $0.70(0.41)$ & 0.78 \\
\hline $5-6$ & $\mathrm{~V}$ & $\mathrm{~L}$ & $0.43(0.51)$ & $348.34(0.001)$ & $0.19(0.66)$ & 0.82 \\
\hline $5-7$ & $\mathrm{~V}$ & $\mathrm{~L}$ & $1.20(0.28)$ & $402.96(0.001)$ & $0.17(0.69)$ & 0.84 \\
\hline $5-8$ & $\mathrm{~V}$ & $\mathrm{~L}$ & $0.65(0.42)$ & $592.76(0.001)$ & $0.14(0.71)$ & 0.89 \\
\hline $6-1$ & $\mathrm{~A}$ & $\mathrm{~L}$ & $1.14(0.29)$ & $11.11(0.001)$ & $2.38(0.13)$ & 0.14 \\
\hline $6-2$ & A & $\mathrm{H}$ & $0.79(0.38)$ & $0.43(0.51)$ & $2.03(0.16)$ & 0.02 \\
\hline $6-3$ & $\mathrm{~V}$ & $\mathrm{~L}$ & $1.42(0.24)$ & $8.61(0.004)$ & $2.17(0.15)$ & 0.11 \\
\hline $6-4$ & $\mathrm{~V}$ & $\mathrm{~L}$ & $3.70(0.058)$ & $23.85(0.001)$ & $3.75(0.057)$ & 0.26 \\
\hline $6-5$ & A & $\mathrm{L}$ & $0.04(0.84)$ & $62.98(0.001)$ & $0.11(0.74)$ & 0.46 \\
\hline $6-6$ & $\mathrm{~V}$ & $\mathrm{~L}$ & $1.91(0.17)$ & $37.43(0.001)$ & $2.03(0.16)$ & 0.34 \\
\hline $6-7$ & $\mathrm{~V}$ & $\mathrm{~L}$ & $0.89(0.35)$ & $51.52(0.001)$ & $1.12(0.29)$ & 0.43 \\
\hline $6-8$ & $\mathrm{~V}$ & $\mathrm{~L}$ & $0.94(0.34)$ & $4.51(0.037)$ & $0.02(0.90)$ & 0.07 \\
\hline
\end{tabular}

a Each row shows the results of a separate analysis of variance. The first and second columns indicate the groups with the higher means of LN (price offer). The third through fifth columns present the F statistic, with its significance level in parentheses, for each of the main and interactive effects. The last column reports the coefficient of determination. 
Table 5

Analyses of variance for price revisions ${ }^{\mathrm{a}}$

\begin{tabular}{|c|c|c|c|c|c|c|c|c|}
\hline \multirow[b]{2}{*}{ Set-period } & \multicolumn{8}{|c|}{ Effects of feedback variances and markets } \\
\hline & $\begin{array}{l}\text { Price } \\
\text { revision }\end{array}$ & $\begin{array}{l}\text { Profit } \\
\text { variance }\end{array}$ & $\begin{array}{l}\text { Price } \\
\text { variance }\end{array}$ & $\begin{array}{l}\text { Variances } \\
\text { (combined) }\end{array}$ & $\begin{array}{l}\text { Profit var. } \\
\text { (incremental) }\end{array}$ & $\begin{array}{l}\text { Price var. } \\
\text { (incremental) }\end{array}$ & Markets & $\mathrm{R}^{2}$ \\
\hline $1-1$ & -195 & 2649 & 450 & $41.76(0.001)$ & $5.98(0.02)$ & $11.34(0.001)$ & $19.37(0.001)$ & 0.58 \\
\hline $1-2$ & -21 & 1366 & 170 & $36.79(0.001)$ & $1.46(0.23)$ & $12.39(0.001)$ & $12.94(0.001)$ & 0.53 \\
\hline $1-3$ & -12 & 0 & 43 & $39.19(0.001)$ & $0.63(0.43)$ & $27.12(0.001)$ & $0.64(0.43)$ & 0.51 \\
\hline $1-4$ & 0 & 0 & 19 & $34.34(0.001)$ & $1.30(0.26)$ & $20.65(0.001)$ & $0.84(0.36)$ & 0.48 \\
\hline $1-5$ & 0 & 0 & 21 & $46.70(0.001)$ & $3.65(0.06)$ & $29.49(0.001)$ & $0.25(0.62)$ & 0.55 \\
\hline $1-6$ & -3 & 0 & 13 & $51.19(0.001)$ & $0.87(0.36)$ & $55.92(0.001)$ & $0.08(0.78)$ & 0.57 \\
\hline $1-7$ & 0 & 0 & 9 & $73.36(0.001)$ & $1.36(0.25)$ & $67.00(0.001)$ & $0.10(0.76)$ & 0.66 \\
\hline $2-1$ & -142 & 2005 & 588 & $24.71(0.001)$ & $15.60(0.001)$ & $0.43(0.51)$ & $0.11(0.74)$ & 0.40 \\
\hline $2-2$ & -59 & 1006 & 78 & $28.00(0.001)$ & $6.52(0.01)$ & $3.32(0.07)$ & $6.41(0.01)$ & 0.45 \\
\hline $2-3$ & -37 & 811 & 37 & $21.02(0.001)$ & $0.58(0.45)$ & $20.96(0.001)$ & $3.35(0.07)$ & 0.37 \\
\hline $2-4$ & -23 & 375 & 19 & $53.27(0.001)$ & $2.45(0.12)$ & $38.65(0.001)$ & $0.04(0.84)$ & 0.58 \\
\hline $2-5$ & -15 & 5 & 9 & $60.62(0.001)$ & $0.20(0.66)$ & $58.66(0.001)$ & $6.95(0.01)$ & 0.63 \\
\hline $2-6$ & -10 & 0 & 5 & $39.17(0.001)$ & $0.73(0.39)$ & $54.58(0.001)$ & $0.64(0.43)$ & 0.51 \\
\hline $2-7$ & -7 & 0 & 4 & $23.27(0.001)$ & $1.21(0.28)$ & $31.27(0.001)$ & $1.61(0.21)$ & 0.39 \\
\hline $3-1$ & 175 & 0 & -26 & $35.70(0.001)$ & $3.95(0.05)$ & $44.14(0.001)$ & $8.48(0.01)$ & 0.51 \\
\hline $3-2$ & 72 & 0 & 1 & $36.93(0.001)$ & $14.83(0.001)$ & $33.36(0.001)$ & $1.53(0.22)$ & 0.50 \\
\hline $3-3$ & 37 & 0 & 5 & $28.57(0.001)$ & $10.74(0.002)$ & $21.83(0.001)$ & $1.60(0.21)$ & 0.44 \\
\hline $3-4$ & 19 & 0 & 16 & $67.03(0.001)$ & $21.13(0.001)$ & $44.26(0.001)$ & $0.18(0.67)$ & 0.64 \\
\hline $3-5$ & 15 & 0 & 4 & $47.21(0.001)$ & $18.52(0.001)$ & $23.03(0.001)$ & $0.03(0.88)$ & 0.55 \\
\hline $3-6$ & 6 & 0 & 4 & $34.71(0.001)$ & $31.09(0.001)$ & $5.19(0.03)$ & $0.70(0.40)$ & 0.48 \\
\hline $3-7$ & 4 & 0 & 4 & $18.49(0.001)$ & $27.14(0.001)$ & $0.19(0.66)$ & $5.78(0.02)$ & 0.36 \\
\hline $4-1$ & 50 & 0 & 13 & $96.70(0.001)$ & $19.36(0.001)$ & $54.30(0.001)$ & $7.78(0.01)$ & 0.73 \\
\hline $4-2$ & 25 & 0 & 13 & $79.71(0.001)$ & $63.37(0.001)$ & $14.94(0.001)$ & $24.15(0.001)$ & 0.71 \\
\hline $4-3$ & 14 & 0 & 4 & $42.60(0.001)$ & $28.32(0.001)$ & $8.35(0.01)$ & $50.81(0.001)$ & 0.64 \\
\hline $4-4$ & 0 & 0 & 5 & $65.71(0.001)$ & $30.73(0.001)$ & $26.51(0.001)$ & $36.86(0.001)$ & 0.69 \\
\hline $4-5$ & 0 & 0 & 2 & $26.22(0.001)$ & $18.04(0.001)$ & $7.70(0.01)$ & $22.13(0.001)$ & 0.50 \\
\hline $4-6$ & 0 & 0 & 1 & $20.48(0.001)$ & $7.42(0.01)$ & $13.25(0.001)$ & $28.68(0.001)$ & 0.48 \\
\hline $4-7$ & 0 & 0 & 2 & $24.80(0.001)$ & $3.52(0.07)$ & $26.01(0.001)$ & $43.52(0.001)$ & 0.55 \\
\hline $5-1$ & -250 & 1965 & 203 & $19.18(0.001)$ & $3.21(0.08)$ & $7.58(0.01)$ & $8.41(0.01)$ & 0.38 \\
\hline $5-2$ & -50 & 599 & 59 & $76.35(0.001)$ & $0.02(0.96)$ & $39.72(0.001)$ & $0.61(0.44)$ & 0.67 \\
\hline $5-3$ & -27 & 0 & 21 & $64.45(0.001)$ & $0.45(0.51)$ & $45.76(0.001)$ & $2.99(0.09)$ & 0.63 \\
\hline $5-4$ & -12 & 0 & 9 & $65.54(0.001)$ & $0.27(0.61)$ & $68.00(0.001)$ & $1.47(0.23)$ & 0.64 \\
\hline $5-5$ & -5 & 0 & 8 & $122.92(0.001)$ & $4.96(0.03)$ & $196.61(0.001)$ & $0.12(0.73)$ & 0.76 \\
\hline $5-6$ & -4 & 0 & 4 & $22.50(0.001)$ & $0.29(0.59)$ & $31.36(0.001)$ & $0.47(0.49)$ & 0.37 \\
\hline $5-7$ & -3 & 0 & 2 & $22.50(0.001)$ & $0.29(0.59)$ & $31.36(0.001)$ & $0.47(0.49)$ & 0.37 \\
\hline $6-1$ & -303 & 1995 & 720 & $3.12(0.05)$ & $1.63(0.21)$ & $0.09(0.76)$ & $6.06(0.02)$ & 0.14 \\
\hline $6-2$ & -100 & 849 & 208 & $6.57(0.002)$ & $0.90(0.35)$ & $1.40(0.24)$ & $1.79(0.19)$ & 0.17 \\
\hline $6-3$ & -50 & 249 & 69 & $7.77(0.001)$ & $0.34(0.57)$ & $4.21(0.04)$ & $0.46(0.50)$ & 0.18 \\
\hline $6-4$ & -20 & 6 & 23 & $44.25(0.001)$ & $0.77(0.38)$ & $40.28(0.001)$ & $0.14(0.71)$ & 0.55 \\
\hline $6-5$ & -10 & 0 & 8 & $8.27(0.001)$ & $1.77(0.19)$ & $15.49(0.001)$ & $1.20(0.28)$ & 0.19 \\
\hline $6-6$ & -6 & 0 & 9 & $4.37(0.02)$ & $0.32(0.57)$ & $4.41(0.04)$ & $4.68(0.03)$ & 0.16 \\
\hline $6-7$ & -2 & 0 & 2 & $8.01(0.001)$ & $1.79(0.19)$ & $5.49(0.02)$ & $36.73(0.001)$ & 0.45 \\
\hline
\end{tabular}

a Each row shows the results of a separate analysis of variance. The first through third columns report the medians for price revision, profit variance, and price variance, respectively. The fourth through seventh columns present the F statistic, with its significance level in parentheses, for the combined effects of profit and price variances, the incremental effect of profit variances after adjusting for price variances and markets, the incremental effect of price variances after adjusting for profit variances and markets, and the main effect for markets, respectively. The last column reports the coefficient of determination. 
$(F=1,154.22, p<0.001)$ and sets $\times$ markets $(F=29.51, p<0.001)$ further indicate the large impact of demand conditions. The significant effects for periods $(F=53.69, p<0.001)$, periods $\times$ sets $(F=67.68, p<0.001)$, and periods $\times$ sets $\times$ markets $(F=8.35, \mathrm{p}<.001)$, are consistent with the convergence results discussed earlier. The significant effect for costing systems $\times$ periods $(F=2.03$, $p<0.05)$ is consistent with $\mathrm{H} 2$. As discussed above, however, the predicted pattern of bias emergence and elimination occurred only in set 1 . Finally, it is noteworthy that costing systems had an insignificant effect on long-run profitability. The mean ending franc balance was 33,655 $(31,471)$ for sellers with absorption (variable) costing in the lenient markets, and 1706 (1623) for sellers with absorption (variable) costing in the harsh markets.

\subsection{Learning from feedback}

H3 predicted that price revisions depend on feedback regarding profit and price variances. The first to third columns of Table 5 report medians for price revision, profit variance, and price variance, respectively. Sellers typically revised their price offers downward in sets $1,2,5$ and 6 , but upward in sets 3 and 4 . All sets were similar in that price revisions mostly occurred in the early periods. Averaging over sets, $45 \%$ of the total price revision occurred by period $2,65 \%$ by period 3 , and $78 \%$ by period 4 . Large (small) profit variances were typical in the early (late) periods of most, but not all, sets and markets. ${ }^{14}$ Averaging over sets, $78 \%$ of sellers had zero profit variance in period 8. Price variances also approached zero. Averaging over sets, the median price variance decreased from 325 francs in period 1 to only 4 francs in period 8 . The fourth to seventh columns of Table 5 report an ANOVA for each period using LN (price revision) as the dependent variable, lenient vs harsh markets as a between-subjects factor, and two covariates, i.e. ranked profit

\footnotetext{
${ }^{14}$ The percentage of sellers with trades in sets 3 and 4 started and stayed high (see note 13), resulting in a median profit variance of zero in all periods.
}

and price variances. More precisely, the dependent variable was $+\mathrm{LN}$ (price revision) for upward revisions, -LN (-price revision) for downward revisions, and zero for no revision. Each ANOVA assessed the combined and separate effects of the covariates after removing the effects of markets, which was included as a control variable. The relevant result for $\mathrm{H} 3$ was the combined effects of the feedback variances (column 4 of Table 5). In all periods, the combined effects were significant, which supports $\mathrm{H} 3$.

To assess the relative effects of the feedback variances, two versions of the ANOVA were performed. ${ }^{15}$ One version assessed the effects of price variances and then profit variances, while the other version used the reverse order. The fifth and sixth columns of Table 5 show the incremental effects of profit and price variances, respectively. In period 1 of set 1 , for example, profit variances had a significant effect $(F=5.98, p<0.02)$ on price revisions, after removing the effects of markets and price variances. Price variances also had a significant effect $(F=11.34, p<0.001)$ on price revisions, after removing the effects of markets and profit variances. Generally, price revisions were more closely associated with price variances than with profit variances. The information content of profit variances was somewhat limited in this setting, since an accepted offer implied zero profit variance, and a rejected offer implied a profit variance equal to target profit plus fixed cost.

\subsection{Threat of bankruptcy}

H4 predicts that a greater threat of bankruptcy increases relative price revision in the early periods of a set. Using lenient vs harsh markets to proxy for the threat of bankruptcy, an ANOVA was performed using relative price revision as the dependent variable, with sets (1-5) and periods (1-7) as within-subject factors, and lenient vs harsh

\footnotetext{
15 As expected, the correlation between profit and price variances generally was high, but not perfect. Over periods, Spearman correlations averaged 0.61 , ranging from 0.33 to 0.87 .
} 
markets and absorption vs variable costing as between-subject factors. The third column of Table 3 shows the main and interactive effects. ${ }^{16}$ The relevant result for $\mathrm{H} 4$ was the significant effect for periods x markets $(F=12.85, p<0.001)$. The mean relative price revision for the harsh markets, by period, was $0.50,0.18,0.11,0.08,0.06$, 0.03 , and 0.04 ; the corresponding numbers for the lenient markets were $0.39,0.24,0.15,0.08,0.05$, 0.04 , and 0.05 . The differences between markets were significant in periods 1,2 , and 3 only. The higher relative price revision from period 1 to 2 in the harsh vs lenient markets supports H4. However, it should be emphasized that this effect reversed in the next two periods. Further, earlier analyses revealed that price errors generally were higher in the harsh vs lenient markets. Despite accelerated price revisions, sellers in the harsh markets were more prone to make suboptimal price decisions. ${ }^{17}$

Table 3 shows other significant effects for relative price revision. The effect for periods $(F=374.99, p<0.001)$ resulted from price revisions mostly occurring in early periods. The effect for periods $\times$ sets $(F=3.39, p<0.001)$ resulted from differences in the rate of price revision over sets; price revision was faster in later vs earlier sets. The effect for periods $\times$ sets $\times$ markets $(F=2.85, p<0.001)$ resulted from a difference in the market effect over sets. Consistent with $\mathrm{H} 4$, relative price revision was significantly higher in the harsh vs lenient markets in period 1 of sets 2 , 3,4 and 5 . In period 1 of set 1 , the difference

${ }^{16}$ The absence of main (and certain interactive) effects for sets, markets, and costing systems, was due to the measure of relative price revision. By construction, relative price revision had the same mean (1/7) for each set, market, and costing system. In this way, the measure controlled for the main effects of these variables, while allowing interactive effects for periods and any other factor. H4 involved the interactive effect of markets and periods.

17 These apparently conflicting results may be reconciled by noting that relative price revision measured the percentage of a seller's total revision that occurred in each period of a set, regardless of his total revision or price errors for the set. Comparing the harsh vs lenient markets, larger relative price revisions in period 1 were not incompatible with larger price errors over all periods. between markets was insignificant, which is not surprising given that sellers had to infer demand, and thus the threat of bankruptcy, from actual trades.

\section{Concluding remarks}

Research on cost-based pricing should consider the essential features of the market setting in which such decisions are made. This point applies to experimental studies, as well as to studies using other methods. When designing experiments, the incorporation of market features is facilitated by reliance on experimental economics. The standard procedures for running laboratory markets have been carefully developed and validated by hundreds of studies in the area, and a wealth of empirical evidence provides a basis for expectations about market processes and outcomes in new experiments. Using laboratory markets, researchers can examine information processing and decision making at both the individual and market levels, and address basic issues regarding the effects of individual behavior on aggregate outcomes and the effects of aggregate settings on individual behavior (Berg, Dickhaut \& McCabe, 1995). This study contributed evidence about the effects of absorption vs variable costing on pricing decisions in laboratory product markets. The setting incorporated many market features including seller competition, a trading institution, and endogenous feedback. In contrast with past experiments that used individual settings, the results indicated that a pricing bias due to absorption vs variable costing did not persist. Indeed, there was clear evidence of the bias only in the initial period, when sellers had not yet observed actual trades. Through simple learning processes involving profit and price variances, sellers subsequently revised their price offers toward optimum without regard to unit-cost signals.

Like other laboratory markets, this study's experiment involved many design variables, e.g. type of trading institution, number of sellers, type of decision task, type of public and private information, and so on. In connection with each variable, one 
may question whether the results would be different with an alternative design. The experiment used a posted-price institution, because cost-based pricing in natural settings often involve variants of this institution (Dorward, 1987). Based on evidence from experimental economics, the postedprice institution probably slowed the rate of seller learning, relative to other institutions. The experiment used ten sellers in each market so that, even after bankruptcies, there would be a sufficient number of sellers to warrant competitive equilibrium predictions. In a duopoly, by contrast, the nature of seller learning would be complicated by strategic considerations. The experimental task consisted of making a price offer for a single product that was produced to order. Seller learning would be more difficult if the task involved multiple products, cost allocation over products, and production for inventory as well as current sale. The experiment held demand constant for eight trading periods. Markets with more rapidly changing demand would be less conducive to learning. Finally, the experiment included public information about actual trades. Absent such information, seller learning probably would be slower, with greater reliance on profit variances. Future experiments that vary the design features related to seller learning would be valuable.

Simon (1978) made the point that understanding human problem solving requires the study of information processes, and not just solutions per se. For example, to understand how a chess player wins a game, it is necessary to study his moves (and the opponent's reactions) in each stage of the game, and not just the configuration of pieces at checkmate. Understanding markets, which are a form of human problem solving (cf. Bloomfield, Libby \& Nelson, 1996), analogously requires the study of disequilibrium processes that include individual decision making and learning, and not just the conditions of competitive equilibria. Paraphrasing Smith (1991), why is it that firm decision-makers, who as individuals must cope with cognitive information processing limitations, in the context of economic institutions make decisions that are consistent with predictive models based on individual rationality? Attempts to address this question would benefit from taking seriously both psychologists explanations of individual decision behavior and economists' predictions of equilibrium outcomes. The question involves accounting, because two primary purposes of accounting are to facilitate firm decisions and provide feedback for firm learning. There are limited future gains from trying to explain accounting phenomena in terms of either individual decision processes or efficient equilibrium outcomes, taken separately. Future research should focus on the effects of alternative accounting systems on the disequilibrium behavior (i.e. decision making and learning from feedback) of procedurally rational individuals in relevant organizational or institutional settings.

\section{Acknowledgements}

Helpful comments on earlier drafts were provided by two anonymous reviewers, Dan Dhaliwal, Leslie Eldenburg, Sue Haka, Steve Kachelmeier, Chung Kweon Kim, Eric Noreen, Stan Reynolds, Mike Shields, Vernon Smith, Greg Woodruff, Mark Young, and seminar participants at Hong Kong University of Science and Technology, Memphis University, National Chengchi University, National Sun Yat-sen University, and Tsinghua University.

\section{Appendix A}

This experiment is concerned with decision making in a market setting. There are ten participants in the experiment, including you. Each participant will act as a seller of a product, over a number of periods. The type of product is exactly the same for each seller. Each period, you will make a decision about a sales offer which has two parts:

(1) the price per unit at which you are willing to sell the product, and

(2) the maximum number of units that you are willing to sell at this price.

You will receive at least $\$ 15.00$ at the end of the experiment. The $\$ 15.00$ includes $\$ 5.00$ for showing 
up and $\$ 10.00$ for participating until the end of the experiment. Also, by following the instructions carefully and making good decisions, it is possible to earn another $\$ 20.00$. If you earn the $\$ 20.00$, you will get a total of $\$ 35.00$ when you complete the experiment. If you fail to earn the $\$ 20.00$, then you will get only $\$ 15.00$ when you complete the experiment.

\section{A.1. Overview of market procedure}

Each period, the market procedure will consist of four steps:

Step 1. You, and every other seller, will make a decision regarding a sales offer and write your sales offer on an OFFER SHEET

Step 2. All OFFER SHEETS will be collected by staffers for processing by the computer.

Step 3. The computer will determine which sales offers are accepted by buyers.

Step 4. You will receive feedback for the period, which summarizes the sales made, computes your profit or loss, and updates your cash balance.

\section{A.2. Preliminary information}

\section{A.2.1. Currency}

During the experiment, all monetary figures will be expressed in terms of a special currency, francs. For example, when you make your sales offer, the price per unit will be in francs. When you receive feedback, your profit or loss and cash balance will be in francs. The symbol for a franc is Fr. For example, $100 \mathrm{Fr}$ symbolizes the monetary figure of 100 francs.

\section{A.2.2. Cash balance}

At the beginning of the experiment, you will receive a beginning cash balance of 50,000 Fr. Each period, your cash balance will be updated by adding your profit or subtracting your loss. When you complete the experiment, your cash balance will be converted from francs into a lottery number between 1 and 100, using a conversion rate of 1/1,000. The higher your ending cash balance, the higher your lottery number. Below are some examples:
If your ending cash balance is $80,000 \mathrm{Fr}$, then your lottery number would be $80,000 \times 1$ / 1,000 or 80 .

If your ending cash balance is $40,000 \mathrm{Fr}$, then your lottery number would be $40,000 \times 1$ / 1,000 or 40 .

If your ending cash balance is equal to or greater than $100,000 \mathrm{Fr}$, then your lottery number would be the maximum of 100 .

At the end of the experiment, each seller will play a lottery. To illustrate, suppose Ralph is a seller who has an ending cash balance of 80,000 Fr and a lottery number of 80 . Ralph plays the lottery by drawing a poker chip from a bag without looking inside. The bag contains 100 poker chips labelled with a number between 1 and 100. If Ralph draws a poker chip with a number between 1 and 80 , then he wins $\$ 20.00$. If he draws a poker chip with a number between 81 and 100, then he wins $\$ 0.00$. To repeat, the higher your ending cash balance, the higher your lottery number. And the higher your lottery number, the easier it is to win $\$ 20.00$.

\section{A.2.3. Number of periods}

There will be a minimum of 40 periods. That is, the market procedure will be repeated at least 40 times. You will not know the exact number of periods until the end of the experiment. At that time, a staffer will announce "this is the last period." The periods will be grouped into separate "sets" of 8 periods each. When referring to a specific period, we will use a simple code: Set 1*Period 1 refers to the first period in the first set of periods, Set 1*Period 2 refers to the second period in the first set, and so on.

\section{A.2.4. Buyers' demand for product}

Buyers' demand refers to the relationship between product prices and the total quantity that buyers are willing to buy. Because all units of product are exactly the same, buyers focus only on the product price. When comparing sales offers, buyers always prefer the sales offer with the lowest price per unit. You will not be told anything about the level of buyers' demand in the instructions or by the staffers. The only information that you will receive about the level of buyers' demand will be feedback at the 
end of a period which summarizes sales made in the period. The level of buyers' demand will vary for each set of periods. However, it will stay the same for each period within a set. For example, at the beginning of Set 1*Period 1, the level of buyers' demand will be determined for Set 1 . It will stay the same for Set $1 *$ Period 2, Set $1 *$ Period 3, and so on, through Set 1*Period 8. Then, at the beginning of Set $2 *$ Period 1, buyers' demand will change to a new level and stay at the new level through Set 2*Period 8. Because changes in the level of buyers' demand are random, it is impossible to predict whether the new level will be higher or lower than before.

\section{A.2.5. Limits on unit sales}

When you specify the maximum number of units that you are willing to sell at a certain price, the number you pick must be between one and five, inclusive. It is impossible to sell more units than the maximum number of units that you specify, regardless of buyers' demand. On the other hand, it is possible to sell fewer units. For example, suppose that you offer to sell four units at a certain price per unit. It is impossible for you to sell five units. However, you could sell less than four units. This would happen when buyers are willing to buy, say, only two units at the price you offer.

\section{A.2.6. Your profit or loss}

At the end of each period, you will receive feedback which computes your profit or loss, where: Profit or loss $=$ sales revenue - total cost. Sales revenue equals the number of units that you actually sell multiplied by the price per unit in your sales offer. Total cost has two parts: periodic cost and production cost. Each period, you will incur a periodic cost of $1860 \mathrm{Fr}$. Regardless of what happens, you cannot avoid the periodic cost. In addition, when you sell units, you will incur a production cost which depends on the number of units that you sell, as follows: the first unit has a production cost of $30 \mathrm{Fr}$, the second unit has a production cost of $160 \mathrm{Fr}$, the third unit has a production cost of $160 \mathrm{Fr}$, the fourth unit has a production cost of $650 \mathrm{Fr}$, the fifth unit has a production cost of $650 \mathrm{Fr}$. For example, if you sell four units, your production cost would sum to $1000 \mathrm{Fr}(30 \mathrm{Fr}+160 \mathrm{Fr}+160 \mathrm{Fr}+650 \mathrm{Fr})$.

\section{A.2.7. Cost schedule}

On the OFFER SHEET, you will receive a cost schedule showing the cost per unit, computed for each quantity between one and five units.

\section{1 \\ 2 \\ 2}

\# of units

Cost per Computation unit

$1,890 \mathrm{Fr} \quad 1860 \mathrm{Fr}$ for periodic cost

$30 \mathrm{Fr}$ for producing first unit $1890 \mathrm{Fr} / 1=1890 \mathrm{Fr}$

$1,025 \mathrm{Fr} \quad 1860 \mathrm{Fr}$ for periodic cost

$30 \mathrm{Fr}$ for producing first unit

$160 \mathrm{Fr}$ for producing second unit

$2050 \mathrm{Fr} / 2=1025 \mathrm{Fr}$

3

$737 \mathrm{Fr}$

4

$715 \mathrm{Fr}$

5

$702 \mathrm{Fr}$

\section{A.2.8. Setting a price}

When writing a sales offer on the OFFER SHEET, you will be asked to specify the price in your sales offer by indicating: 
(1) the cost per unit for the number of units that you specify in your sales offer,

(2) an adjustment to the cost per unit,

(3) the price per unit, by combining the cost per unit and the adjustment.

Your adjustment to the cost per unit may be upward or downward. However, there are two constraints on your adjustment. First, you may not specify an adjustment such that the price is negative. Second, you may not specify an adjustment such that the price is above 2000 Fr. In other words, your price per unit must be in the range from $0 \mathrm{Fr}$ to $2000 \mathrm{Fr}$.

\section{A.2.9. Bankruptcy}

It is possible for you to go bankrupt. This would occur if your remaining cash balance at the end of a period is negative. If you go bankrupt, you may not continue to participate in the experiment or play the lottery. Instead, you will be paid $\$ 15.00$ for showing up and participating and then asked to leave the room.

\section{A.2.10. Offer sheet}

Below is a schedule for the cost per unit (as computed earlier):

\# of Units
1
2
3
4
5

Cost per Unit

$1,890 \mathrm{Fr}$

$1,025 \mathrm{Fr}$

$737 \mathrm{Fr}$

$715 \mathrm{Fr}$

$702 \mathrm{Fr}$

Enter your offer for next period:

Maximum number of units

that you are willing to sell

(must be between 1 and 5 units)

Cost per unit

\pm Adjustment to cost per unit

$=$ Price per unit offered units $\mathrm{Fr}$ $\mathrm{Fr}$ Fr

\section{References}

Arkes, H., \& Hammond, K. (1986). Judgment and decision making. Cambridge, UK: Cambridge University Press.
Arkes, H., \& Blumer, C. (1985). The psychology of sunk cost. Organizational Behavior and Human Decision Performance, $35,124-140$.

Ashton, R. (1976). Cognitive changes induced by accounting changes: Experimental evidence on the functional fixation hypothesis. Journal of Accounting Research, 14, 1-17.

Ashton, A. (1981). Descriptive study of information evaluation. Journal of Accounting Research, 19, 42-61.

Barnes, P., \& Webb, J. (1986). Management information changes and functional fixation: Some experimental evidence from the public sector. Accounting, Organizations and Society, 11, 1-18.

Berg, J., Dickhaut, J., \& McCabe, K. (1995). The individual versus the aggregate (Eds.). In R. Ashton and A. Ashton. Judgment and decision-making research in accounting and auditing Cambridge, UK: Cambridge University Press.

Blaug, M. (1992). The methodology of economics (2nd Ed.). Cambridge, UK: Cambridge University Press.

Bloomfield, R. (1997). Strategic dependence and the assessment of fraud risk: A laboratory study. The Accounting Review 72, 517-538.

Bloomfield, R., Libby, R., \& Nelson, M. (1996). Communication of confidence as a determinant of group judgment accuracy. Organizational Behavior and Human Decision Processes, 68, 287-300.

Bonner, S., Young, M., \& Hastie, R. (1996). Incentive effects on the performance of laboratory tasks, Working Paper, University of Colorado.

Camerer, C. (1987). Do biases in probability judgment matter in markets? Experimental evidence. American Economic Review, 77, 981-997.

Camerer, C. (1992). The rationality of prices and volume in experimental markets. Organizational Behavior and Human Decision Processes, 51, 237-272.

Camerer, C., Loewenstein, G., \& Weber, M. (1989). The curse of knowledge in economic settings. Journal of Political Economy, 97, 1232-1254.

Cox, J., \& Grether, D. (1996). The preference reversal phenomenon: response mode, markets and incentives. Economic Theory, 7, 381-405.

Cyert, R., \& March, J. (1992). A behavioral theory of the firm (2nd Ed.). Oxford, UK: Basil Blackwell.

Davis, D., \& Holt, C. (1993). Experimental Economics. Princeton, NJ: Princeton University Press.

Dickhaut, J., \& Lere, J. (1983). Comparison of accounting systems and heuristics in selecting economic optima. Journal of Accounting Research, 48, 495-513.

Dorward, N. (1987). The pricing decision: Economic theory and business practice. London: Harper and Row

Duh, R., \& Sunder, S. (1986). Incentives, learning and processing of information in a market environment: An examination of the base rate fallacy, In S. Moriarty (Eds.), Laboratory market research. Norman, OK: Univeristy of Oklahoma.

Dyckman, T., Hoskin, R., \& Swieringa, R. (1982). An accounting change and information processing changes. Accounting, Organizations and Society, 7, 1-12.

Erev, I., \& Roth, A. (1998). Predicting how people play games: Reinforcement learning in experimental games with unique, 
Mixed strategy equilibria. American Economic Review, 88, 848881.

Frey, B., \& Eichenberger, R. (1994). Economic incentives transform psychological anomalies. Journal of Economic Behavior and Organization, 23, 215-234.

Friedman, D., \& Sunder, S. (1994). Experimental methods: A primer for economists. Cambridge, UK: Cambridge University Press.

Gangully, A., Kagel, J., \& Moser, D. (1994). The effects of biases in probability judgments on market prices. Accounting, Organizations and Society, 19, 678-700.

Gode, D., \& Sunder, S. (1993). Allocative efficiency of markets with zero intelligence traders: Market as a partial substitute for individual rationality. Journal of Political Economy, 101, 119-137.

Govindarajan, V., \& Anthony, R. (1983). How firms use cost data in price decisions. Management Accounting, 64, 30-36.

Gupta, M., \& King, R. (1996). An experimental investigation of the effect of cost information and feedback on product cost decisions. Contemporary Accounting Research, 14, 99127.

Hilton, R., Swieringa, R., \& Turner, M. (1988). Product pricing, accounting costs, and use of product-costing systems. The Accounting Review, 53, 195-215.

Hogarth, R., \& Reder, M. (1986). The behavioral foundations of economic theory. The Journal of Business, 59.

Hopwood, A. (1978). Toward an organizational perspective for the study of accounting and information systems. Accounting, Organizations and Society, 3, 3-14.

Jamal, K., \& Sunder, S. (1996). Bayesian equilibrium in double auctions populated by biased heuristic traders. Journal of Economic Behavior and Organization, 31, 273-291.

Kachelmeier, S. (1996). Do cosmetic reporting variations affect market behavior? A laboratory study of the accounting emphasis on unavoidable costs. Review of Accounting Studies, 1, 115-140.

Kahneman, D., Slovic, P., \& Tversky, A. (1982). Judgment under uncertainty: Heuristics and biases. Cambridge, UK: Cambridge University Press.

Kahneman, D., \& Tversky, A. (1972). Subjective probability: A judgment of representativeness. Cognitive Psychology, 3, 430454.

Kaplan, R., \& Atkinson, A. (1998). Advanced management accounting (3rd Ed.). Upper Saddle River, 363NJ: Prentice Hall.

Lere, J. (1986). Product pricing based on accounting costs. The Accounting Review, 61, 318-324.

Levitt, B. \& March, J. (1986). Organization learning. Annual Review of Sociology, 14, 319-340.

Libby, R. (1976). Discussion of cognitive changes induced by accounting changes: Experimental evidence on the functional fixation hypothesis. Journal of Accounting Research, $14,18-24$.

Libby, R. (1990). Experimental research and the distinctive features of accounting settings. In: T. Frecka, T. (Ed.), The state of accounting research as we enter the 1990s. Urbana, IL: University of Illinois.

Lichtenstein, S., \& Slovic, P. (1971). Reversals of preference between bids and choices in gambling decisions. Journal of Experimental Psychology, 89, 46-55.

Lopes, L. (1994). Psychology and economics: Perspectives on risk, cooperation, and the market place. Annual Review of Psychology, 45, 197-227.

Milgrom, S., \& Roberts, J. (1992). Economics, organization and management. Englewood Cliffs, NJ: Prentice Hall.

Nelson, R., S. Winter, An evolutionary theory of economic change Cambridge, MA: Belknap.

Neter, J., Kutner, M., Nachtsheim, C., \& Wasserman, W. (1996). Applied linear statistical models. Chicago: Irwin.

Oxenfeldt, A., \& Baxter, W. (1961). Approaches to pricing: Economist versus accountant. Business Horizons, 77-90.

Roth, A., \& Erev, I. (1995). Learning in extensive-form games: Experimental data and simple dynamic models in the intermediate term. Games and Economic Behavior, 8, 164-212.

Shim, E., \& Sudit, E. (1995). How manufacturers price products. Management Accounting, 76, 37-39.

Simon, H. (1976). From substantive to procedural rationality, In S. Latsis (Ed.), Method and appraisal in economics. Cambridge, UK: Cambridge University Press.

Simon, H. (1978). Information-processing theory of human problem solving, In W. Estes (Ed.), Handbook of learning and cognitive processes, Vol. 5. Hillsdale, NJ: Lawrence Erlbaum.

Simon, H. (1982). Models of bounded rationality: Behavioral economics and business organization. Cambridge, MA: MIT Press.

Simon, H. (1986). Rationality in psychology and economics. The Journal of Business, 59, S209-224.

Slovic, P. \& Lichtenstein, S. (1983). Preference reversals: A broader perspective. American Economic Review, 73, 596-605.

Smith, V. (1991). Rational choice: the contrast between economics and psychology. Journal of Political Economy, 99, 877-897.

Smith, V. \& Walker, J. (1993). Monetary rewards and decision cost in experimental economics. Economic Inquiry, 31, 245261.

Swieringa, R., Dyckman, T. \& Hoskin, R. (1979). Empirical evidence about the effects of an accounting change on information processing, In T. Burns (Ed.), Behavioral experiments in accounting II. Columbus: Ohio State University.

Swieringa, R., \& Weick, K. (1982). An assessment of laboratory experiments in accounting. Journal of Accounting Research, Supplement, 20, 56-101.

Turner, M., \& Hilton, R. (1989). Use of accounting productcosting systems in making production decisions. Journal of Accounting Research, 27, 297-312.

Tversky, A., \& Kahneman, D. (1974). Judgment under uncertainty: Heuristics and biases. Science, 185, 1124-1131.

Tversky, A., \& Kahneman, D. (1986). Rational choice and the framing of decisions. The Journal of Business, 59, S251-S278.

Waller, W. (1995). Decision-making research in managerial accounting: Return to behavioral-economics foundations, in R. Ashton and A. Ashton (Eds.), Judgment and decisionmaking research in accounting and auditing Cambridge, UK: Cambridge University Press. 